\title{
PROJETO E DESENVOLVIMENTO DE UM APARELHO PARA AVALIAR A FORÇA MUSCULAR ISOMÉTRICA DOS ROTADORES DO OMBRO
}

\section{PATRÍCIA MOURA SOUZA}

Dissertação apresentada ao Programa de PósGraduação Interunidades em Bioengenharia Escola de Engenharia de São Carlos Faculdade de Medicina de Ribeirão Preto e Instituto de Química de São Carlos da Universidade de São Paulo para a obtenção do título de Mestre em Bioengenharia.

ORIENTADOR: Prof. Dr. Nilton Mazzer

São Carlos - SP

2003 


\section{DEDICATÓRIA}

Ao meu Pai que esteve orgulhoso e do meu lado no início deste trabalho, levado por Deus no meio dele, mas intensamente vivo dentro de mim para que juntos possamos alcançar o nosso objetivo. 


\section{AGRADECIMENTOS}

A Deus, que levou pro céu grande parte de mim, mas deixou comigo a vontade de lutar e a chance de descobrir que meus esforços não serão em vão.

Ao Prof. Dr. Nilton Mazzer, pela orientação, pelo incentivo e credibilidade incondicional.

Ao Prof. Dr. Cláudio Henrique Barbieri, pela colaboração na realização desse trabalho.

Ao Prof. Dr. José Baptista Portugal Paulin, pela receptividade e acolhida no Laboratório de Bioengenharia.

Aos Engenheiros Antônio Carlos Shimano e Carlos Alberto Moro, pelos ensinamentos, interesse e dedicação no projeto.

Ao Luís Henrique Alves Pereira, pelo apoio, solidariedade, amizade e preciosa dedicação durante a realização deste trabalho.

Aos funcionários do Laboratório, Francisco Carlos Mazzocato e Maria Teresinha de Moraes pelo companheirismo e pela colaboração fundamental.

Aos funcionários da Oficina de Precisão da Prefeitura da FMRP - USP, em especial ao Octávio e Ednilson.

Às secretárias de pós-graduação, Janete Ferreira Rodrigues dos Santos e Maria de Fátima Feitosa de Lima.

Ao Dr. José Wagner de Barros (in memorian), por me orientar sobre a importância em manter o idealismo nos olhos e os pés no chão.

Aos colegas pós-graduandos, pelo companheirismo durante estes anos.

À minha família, pelo exemplo de dignidade invulnerável e por me fornecer suporte nos momentos mais difíceis, em especial à minha mãe, ao Tovar e ao Wagner pela presença, tolerância e compreensão. 
LISTA DE FIGURAS i

LISTA DE ABREVIATURAS E SIGLAS ii

RESUMO iii

ABSTRACT iv

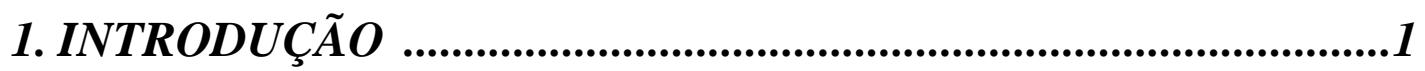

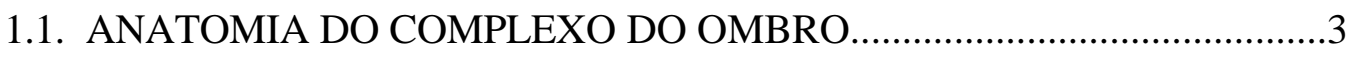

1.1.1. Articulação escapulotorácica..................................................... 3

1.1.2. Articulação esternoclavicular........................................................

1.1.3. Articulação acromioclavicular...........................................................4

1.1.4. Articulação glenoumeral...................................................................4

1.1.5. Articulação subacromial ou supra-umeral........................................8

1.1.6. Os músculos e suas funções no complexo do ombro........................9

1.2. ASPECTOS DA BIOMECÂNICA ESCAPULOUMERAL ..........................11

1.3. DESEQUILÍBRIOS MUSCULARES DOS ROTADORES DO OMBRO..15

1.4. SISTEMAS DE AVALIAÇÃO DA FORÇA MUSCULAR................... 18

1.4.1. Avaliação da força muscular do ombro.................................................24

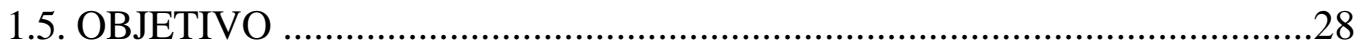

2. MATERIAL E MÉTODO..........................................................29

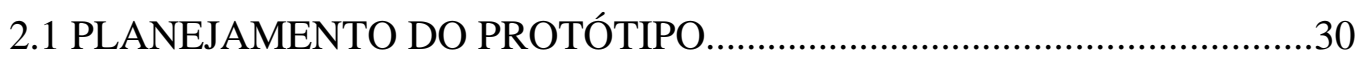

2.1.1. Definição do modelo...................................................................................30

2.1.1. Dimensionamento do protótipo..............................................................

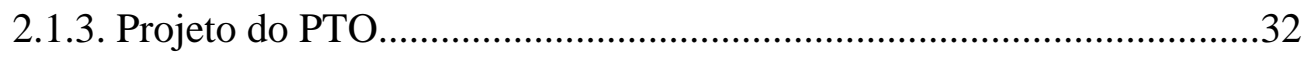

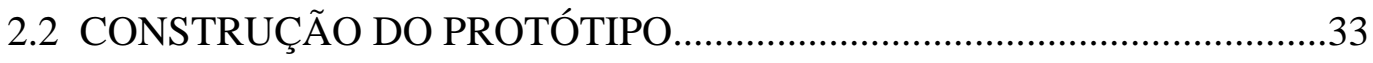

2.2.1.Base de sustentação..........................................................................33

2.2.2.Plataforma de medição da força de rotação do ombro...........................35

2.2.3.Fixação do instrumento de medida...........................................................36

2.2.4.Leitura da força aplicada e calibração do PTO......................................38

2.3. TESTES DE EFICIÊNCIA E ADAPTABILIDADE DO PROTÓTIPO EM 
2.4. VERSÃO FINAL DO APARELHO..........................................................40

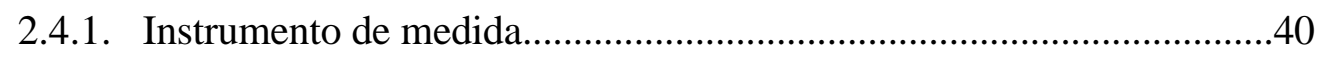

2.4.1.1.Calibração do Torquímetro..........................................................42

2.4.2. Base de Sustentação do PTO..............................................................43

2.4.3. Haste de apoio do antebraço...........................................................45

2.5. TESTE DE EFICIÊNCIA E ADAPTABILIDADE DA VERSÃO FINAL

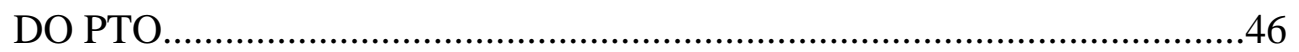

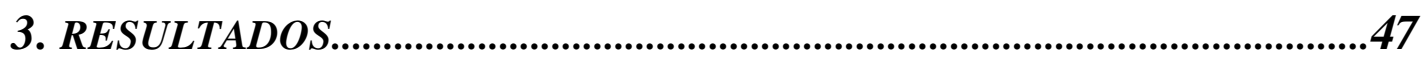

3.1. ADAPTAÇÃO DO PTO ÀS VARIAÇÕES ANTROPOMÉTRICAS DOS INDIVÍDUOS.

3.2. EFICÁCIA DO PTO NA AVALIAÇÃO DA FORÇA MUSCULAR DOS ROTADORES DO OMBRO...................................................................50

3.3. TOLERÂNCIA RELATADA PELOS INDIVÍDUOS SUBMETIDOS AOS ESFORÇOS ISOMÉTRICOS UTILIZANDO O

PTO .50

3.4. CUSTO APROXIMADO DO APARELHO DESENVOLVIDO PARA AVALIAR O TORQUE DOS ROTADORES DO

OMBRO. .51

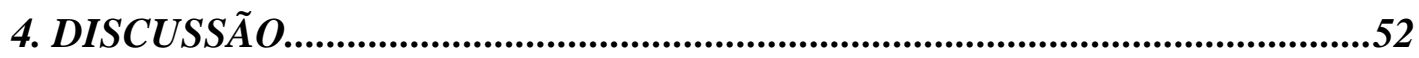

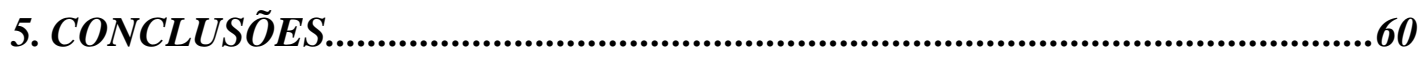

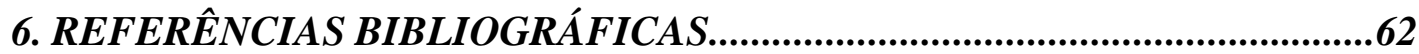

7.ANEXOS

8. APÊEDICE 


\section{LISTA DE FIGURAS}

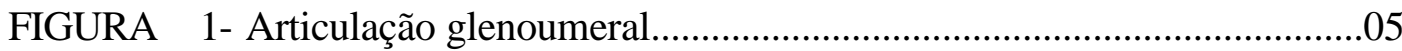

FIGURA 2- Articulação subacromial....................................................................

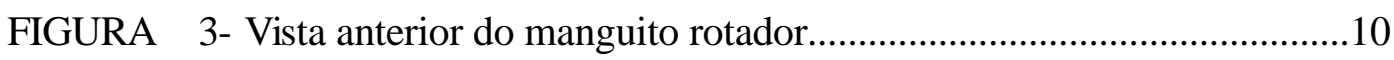

FIGURA 4- Vista posterior do manguito rotador....................................................10

FIGURA 5-Mecanismo de force couple entre os músculos do manguito rotador e o deltóide.

FIGURA 6- Processo cíclico da patologia do manguito rotador .16

FIGURA 7- Padrão semiológico para teste de força muscular manual....................21

FIGURA 8- Medidas utilizadas no dimensionamento do PTO.................................32

FIGURA 9- Desenho esquemático do protótipo...................................................33

FIGURA 10-Protótipo do aparelho desenvolvido para avaliar a força muscular isométrica dos rotadores do ombro

FIGURA 11-Vista superior da plataforma de força sobre a qual os testes de força muscular foram realizados .36

FIGURA 12-Vista lateral do PTO. .37

FIGURA 13-Exemplo de utilização do PTO em angulação de rotação interna do ombro.

FIGURA 14-Exemplo de utilização do PTO em angulação de rotação externa do ombro .40

FIGURA 15- Desenho esquemático do torquímetro 41

FIGURA 16-Gráfico demonstrativo torque/indicador da calibração do torquímetro.

FIGURA 17- Desenho esquemático da versão final do PTO.

FIGURA 18- Sistema de controle da angulação de rotação do tubo telescopável....44

FIGURA 19- Haste de apoio do antebraço com a escala em centímetros.....................46

FIGURA 20- Goniômetro fixado sob as cremalheiras . .46

FIGURA 21- Versão final do PTO. .48

FIGURA 22 - Vista lateral da versão final do PTO . .49 
LISTA DE ABREVIATURAS E SIGLAS

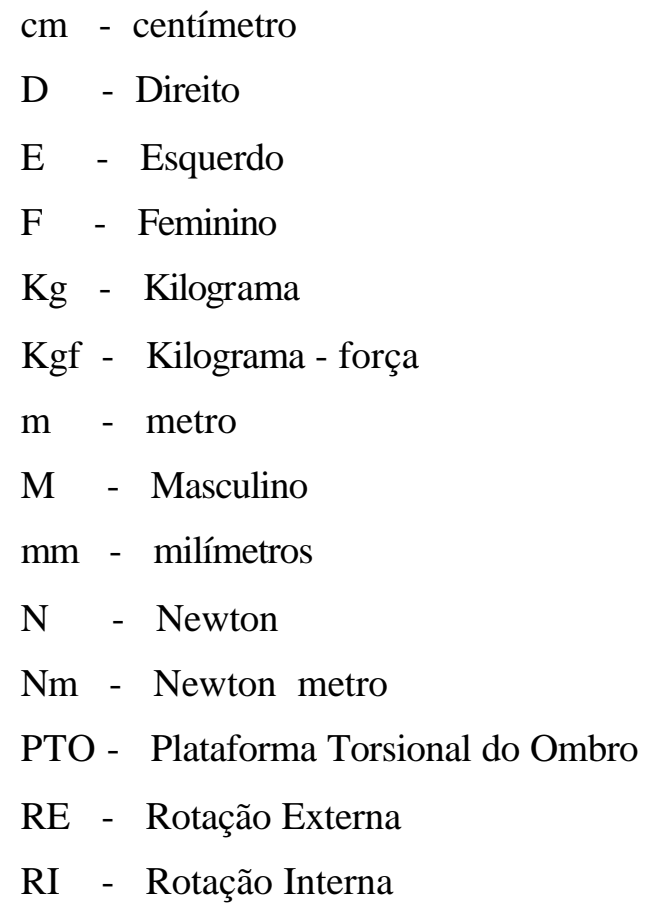




\section{ABSTRACT}

The rotator cuff muscles are responsible for the rotation movements of the shoulder and frequent site of pathological processes. Rotator cuff muscle power imbalance may unchain or result from distinct shoulder diseases. To date precise quantification of rotator cuff muscle power is only possible with the use of expensive machines, far from the reach of most of the professionals involved with the problem in our country. In the present investigation, a relatively simple and low cost device, able to precisely measuring isometric internal and external rotator muscle power, was developed and built with easily obtainable and low cost materials. It consists basically of a platform for measuring the rotational torque of the shoulder adaptable to both sides of a chair for bilateral evaluation. It was designed for the individual to remain seated while in test, the elbow flexed at $90^{\circ}$ and the forearm rested on a flat surface. A properly calibrated torquimeter was adapted to the bottom side of the platform in a point corresponding to the shoulder's center of rotation. The moving lever was provided with a handle to be grasped by the individual while doing internal or external efforts with the shoulder. Both platform height and moving lever were made adaptable to individual arm and forearm lengths. The device was tested with 20 healthy individuals and demonstrated to be quite versatile for use in many different conditions and reliable in providing information on the torque of the rotator muscle of the shoulder.

Key-words: biomechanics; shoulder; rotator cuff; muscle strength. 


\section{RESUMO}

SOUZA, P. M. Projeto e desenvolvimento de um aparelho para avaliar a força muscular isométrica dos rotadores do ombro, Ribeirão Preto, 2003. Dissertação (Mestrado) - Escola de Engenharia de São Carlos/ Faculdade de Medicina de Ribeirão Preto/ Instituto de Química de São Carlos, Universidade de São Paulo, 2003.

Os músculos do manguito rotador são os responsáveis pelo movimento de rotação do ombro e representam sítio freqüente de processos patológicos.O desequilíbrio de forças do manguito rotador pode desencadear patologias distintas do ombro ou ser resultado destas. A quantificação da força muscular do manguito rotador com dados precisos, somente é possível com aparelhos de alto custo, longe do alcance da maioria dos profissionais envolvidos com o problema em nosso país. No presente estudo, um aparelho relativamente simples e de baixo custo, capaz de mensurar com precisão a força muscular isométrica de rotação interna e rotação externa do ombro, foi projetado e construído com materiais de fácil obtenção e preço acessível. Ele consiste basicamente de uma plataforma de medição do torque de rotação do ombro acoplada a uma cadeira e adaptável para avaliação bilateral. $\mathrm{O}$ aparelho foi projetado para que o indivíduo permaneça sentado durante o teste, com cotovelo fletido a 90 graus e o antebraço apoiado sobre uma superfície plana. Um torquímetro, devidamente calibrado, foi fixado na porção inferior da plataforma, no ponto correspondente ao centro de rotação do ombro. A mudança no comprimento do braço de alavanca foi permitida pela variação na posição de um manípulo para apoio da mão durante os esforços de rotação interna e de rotação externa do ombro. Variações no comprimento do braço de alavanca e na altura da plataforma foram projetadas para adaptarem-se aos braços e antebraços dos indivíduos. $\mathrm{O}$ aparelho foi testado em 20 indivíduos saudáveis e demonstrou ser completamente versátil para uso em diversas condições e confiável na produção de informações sobre o torque dos músculos rotadores do ombro.

Palavras-chave: biomecânica; ombro; manguito rotador; força muscular. 
1. INTRODUÇÃO




O movimento humano se tornou alvo de muitos estudos, atraídos talvez pela complexidade, versatilidade e precisão de seu funcionamento.

Curiosamente, há mais de uma década, o Committee on Trauma Research da Academia Nacional de Ciência Norte-Americana relatava que a prevenção das lesões para a maioria dos tipos de atividade esportiva continuava quase sem pesquisa. Essa informação é fundamental e correta até mesmo na atualidade. Na obra Injury in América, este Comitê reforçou o importante papel da pesquisa biomecânica na prevenção da lesão, tendo chegado a conclusões como: “deve ser dada a mais alta prioridade à pesquisa capaz de proporcionar uma compreensão mais clara dos mecanismos de lesão" e ainda "é necessário quantificar as respostas relacionadas à lesão" (WHITING \& ZERNICKE, 2001).

Os músculos que movem o conjunto dos segmentos corporais são freqüentemente avaliados a fim se de zelar pela integridade do sistema, prevenindo e identificando lesões.

No membro superior, entretanto, os métodos de análise cinesiológica não são tão precisos e definidos como para o membro inferior. A magnitude das rotações e a impossibilidade de avaliar corretamente a cinemática tridimensional do ombro e da mão seguem dando lugar a numerosas hipóteses. Dados normativos são escassos e muitas variáveis não são passivas de controle, logo, os métodos de análise e tratamento dos desequilíbrios biomecânicos deste segmento geralmente são obtidos por dedução (BLANC \& VIEL, 1994). 


\subsection{ANATOMIA DO COMPLEXO DO OMBRO}

Para atender as necessidades funcionais do membro superior, o ombro adaptou-se e desenvolveu a maior de todas as amplitudes de movimento das articulações do corpo. Essa quantidade de movimento causou a perda da estabilidade inerente ao conjunto de articulações do ombro, e foi descrito por Galeno como "o antagonismo entre a diversidade de movimentos e a segurança da construção" (JOBE, 1990).

O ombro não se resume a uma única articulação, mas se organiza morfofuncionalmente em um complexo articular que possibilita diferentes ações. Ao estudar ou examinar esta região, devemos considerá-la como um complexo articular que mantém relações de interdependência na busca das condições da dinâmica articular: a mobilidade com estabilidade (SOUZA, 2001).

A cintura escapular tem sido estudada mais detalhadamente nos últimos anos e muitas dúvidas relacionadas às origens dos mecanismos de lesão ainda não estão esclarecidas (LECH, 1995).

\subsubsection{Articulação escapulotorácica}

É uma articulação fisiológica de movimento livre, sem qualquer restrição ligamentar. Uma grande quantidade de movimento ocorre entre a fáscia do músculo serrátil anterior e a fáscia do tórax. O funcionamento normal da articulação escapulotorácica é essencial para a mobilidade e estabilidade da extremidade superior (SMITH et al., 1997). 


\subsubsection{Articulação esternoclavicular}

Esta une o membro superior com o esqueleto axial, especificamente à extremidade proximal da clavícula com o manúbrio esternal. É uma articulação do tipo selar, que permite movimentos fundamentais à dinâmica do complexo articular do ombro. Está envolvida principalmente na retração e protação da cintura escapular (KAPANDJI, 1990).

\subsubsection{Articulação acromioclavicular}

A articulação acromioclavicular une a faceta articular lateral da clavícula e a área côncava da parte anterior da borda medial do acrômio (SOUZA, 2001).

Esta articulação possui três eixos e três graus de liberdade de movimento, que são refletidos nos movimentos escapulares. Durante a elevação completa do braço, a articulação acromioclavicular contribui com 20 graus de rotação para cima (INMAN et al., 1944). NEER (1984), entretanto, mediu um máximo de 08 graus de movimento acromioclavicular e afirmou que nenhuma perda de rotação da escápula foi evidente com a fixação da articulação acromioclavicular.

\subsubsection{Articulação glenoumeral}

Embora a articulação glenoumeral seja denominada como uma articulação do tipo bola e soquete, esferóide ou universal e possua três graus de liberdade de movimento, a articulação em pouca estabilidade óssea. A cabeça do úmero de forma esférica repousa sobre o pequeno e raso plano inclinado da cavidade glenóidea (SMITH et al., 1997). Rodeando o bordo glenóideo, existe um labro ou lábio 
cartilaginoso. A cápsula articular frouxa e fina cobre a articulação desde o colo da glenóide até o colo anatômico do úmero.

A desproporção entre o tamanho da cavidade glenóidea e a cabeça do úmero torna o contato das superfícies articulares assimétrico, sendo que a posição de maior congruência é obtida quando o úmero está abduzido e rodado lateralmente (WARWICH \& WILLIANS, 1973).

O lábio glenoidal pode aumentar a profundidade da cavidade glenóidea, com a finalidade de melhorar a estabilidade articular, embora SARRAFIAN (1983) não considere esse efeito significativo. A FIGURA 1 apresenta a articulação glenoumeral.

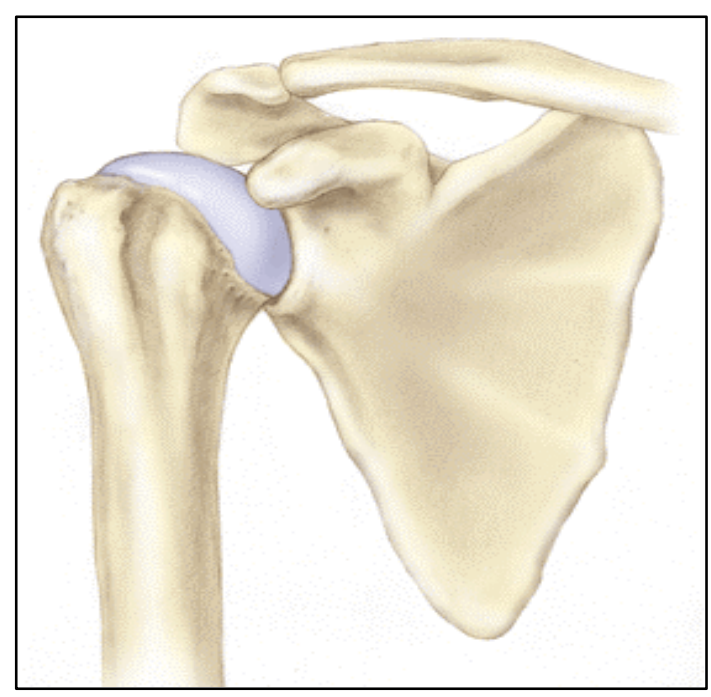

Figura 1 - Articulação glenoumeral (Fonte: Kioschos, 2001).

A cápsula é formada por tecido conjuntivo frouxo. Ela possibilita o movimento dentro de distâncias limitadas, adapta-se encurtamento e fixação se não houver nenhum movimento, ou se alonga lentamente sob tensão prolongada (FERRARI, 1990). 
PEAT (1986) relatou que o reforço da cápsula posterior é fornecido pelos músculos redondo menor e infra-espinhoso; inferiormente, a cápsula é fina e elástica, não desenvolvendo papel importante na estabilidade glenoumeral.

Quanto aos movimentos da articulação glenoumeral, são descritos: (1) flexão e extensão: no plano sagital, no eixo transversal com amplitude média de 170 graus para flexão e 60 graus para extensão; (2) abdução e adução: no plano frontal, no eixo horizontal dorsoventral, com amplitude média de 170 graus para abdução e o movimento de adução é considerado como sendo o retorno da abdução até o contato do braço com o tronco; (3) rotação interna e externa: no plano horizontal, com eixo longitudinal, e amplitude média de 90 graus para rotação externa e 90 graus para rotação interna. A quantidade de rotação muda com a elevação do braço. Aproximadamente 180 graus de rotação estão presentes quando o braço está ao lado e são reduzidos para cerca de 90 graus em virtude da torção e retesamento dos ligamentos coracoumerais e glenoumerais, quando o braço está completamente elevado. Quando a articulação glenoumeral é colocada na posição goniométrica padrão, ou seja, 90 graus de abdução do ombro e 90 graus de flexão do cotovelo, a amplitude normal de movimento para rotação interna é de aproximadamente 70 graus e para rotação externa, 90 graus (NORKIN \& WHITE, 1995).

BROWN et al., (1988) encontraram 141 graus de rotação externa em arremessadores de beisebol da liga principal e CHANG et al., (1988) observaram 78 graus para este movimento em levantadores de peso norte-americanos. Outros movimentos são descritos: adução horizontal é um movimento anterior a partir da posição de 90 graus de abdução glenoumeral; abdução horizontal é um movimento posterior a partir da posição inicial de 90 graus de abdução glenoumeral (SMITH et 
al., 1997) e circundução, que consiste de um movimento combinado nos três eixos, descrevendo um cone irregular no espaço (KAPANDJI, 1990).

HARRYMAN et al., (1990) utilizando um sensor de posição tridimensional, assim como transdutores de força, relataram o movimento de translação da cabeça do úmero com o movimento glenoumeral passivo. Eles observam uma translação anterior significativa durante a flexão glenoumeral e translação posterior com extensão e rotação externa.

Além dos movimentos de translação anterior e posterior, a cabeça do úmero move-se distal e lateralmente à cavidade glenoumeral, cerca de um centímetro (KALTENBORN, 1980).

Em uma articulação glenoumeral normal, uma pequena pressão intracapsular negativa ajuda a estabilizar a articulação. Apesar de não ser particularmente grande, como referido por SPEER (1995), assim mesmo essa força contribui para manter a estabilidade glenoumeral através de sua amplitude de movimento.

Os estabilizadores dinâmicos da articulação glenoumeral incluem um grande número de músculos inseridos na região, que realizam movimentos sincrônicos além de fornecer estabilidade.

O tendão da cabeça longa do bíceps braquial, por exemplo, corre sobre a cabeça umeral e desce no sulco intertubercular. Quando o músculo se contrai, ocorre tensão no tendão para produzir uma força para baixo e para dentro sobre a cabeça do úmero, comprimindo-a contra a cavidade glenóidea. Assim, quando o cotovelo é flexionado com um peso na mão, o bíceps ajuda a impedir a subluxação da articulação glenoumeral (SMITH et al., 1997). 


\subsubsection{Articulação subacromial ou supra-umeral}

Os movimentos da articulação glenoumeral exigem grandes movimentos entre a cabeça do úmero e o arco formado pelo colo da escápula, o processo do acrômio, o ligamento coracoacromial rígido e o processo coracóide. Esta área corresponde à articulação subacromial e foi também denominada desfiladeiro do supra-espinhoso por NEER (1983).

A importância clínica desta área, segundo ROCKWOOD \& MATSEN (1990) é a propensão à compressão e lesão dos tecidos moles que residem entre as estruturas rígidas: os tendões do manguito rotador, especialmente o supra-espinhoso, o tendão da cabeça longa do bíceps braquial, a cápsula, os ligamentos capsulares e as bolsas subdeltóidea e subacromial (FIGURA 2).

Infelizmente, não há espaço para erro funcional ou estrutural no desfiladeiro do supra-espinhoso, e as lesões de colisão ocorrem por fraqueza muscular, fadiga ou forças desequilibradas (REID et al., 1987).

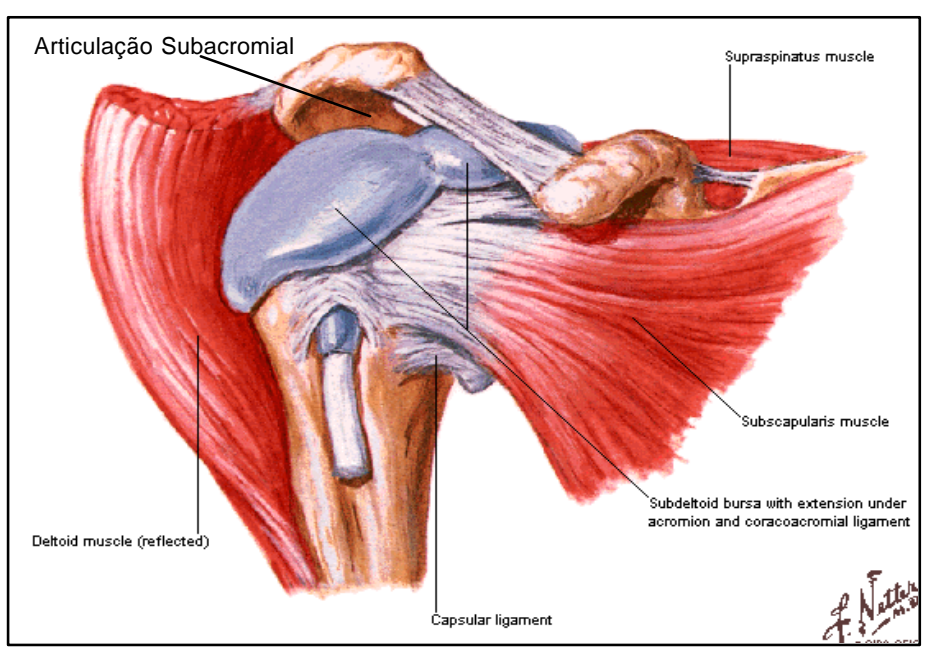

Figura 2- Articulação subacromial (Fonte: Netter, 1996). 


\subsubsection{Os músculos e suas funções no complexo do ombro}

Ações isoladas dos músculos em atividades do membro superior são dificilmente conseguidas. O sinergismo, ajuste e equilíbrio postural deste complexo geralmente recrutam vários músculos no controle do movimento.

KIBLER (1995) relatou que $54 \%$ da força e $51 \%$ da energia cinética produzida pelo membro superior em um gesto esportivo de lançamento são resultado da ação dos membros inferiores, dos quadris e do tronco.

Os músculos mais ativos nos movimentos do ombro são: o manguito rotador, serrátil anterior, trapézio, elevador da escápula, rombóide maior e rombóide menor, grande dorsal, peitoral maior, peitoral menor e deltóide.

O manguito rotador formado por quatro músculos, constitui o alvo mais marcante nos processos etiopatogênicos do ombro e qualquer alteração no equilíbrio de força entre esses músculos resultaria em patologias distintas (FONGEMIE et al., 1998). Os tendões de quatro músculos escapuloumerais curtos que produzem rotação interna e rotação externa da articulação glenoumeral fundem-se com a cápsula e formam as suas fixações distais nas tuberosidades do úmero. Anteriormente, o subescapular fixa-se por um tendão largo no tubérculo menor do úmero. A parte inferior da cápsula e o subescapular são as principais estruturas que limitam a rotação externa. Superiormente, o músculo supra-espinhoso fixa-se no tubérculo maior do úmero, e posteriormente o infra-espinhoso e o redondo menor fundem-se com a cápsula para fixarem-se mais embaixo na tuberosidade maior. As FIGURAS 3 e 4 mostram a arquitetura dos músculos do manguito rotador. 


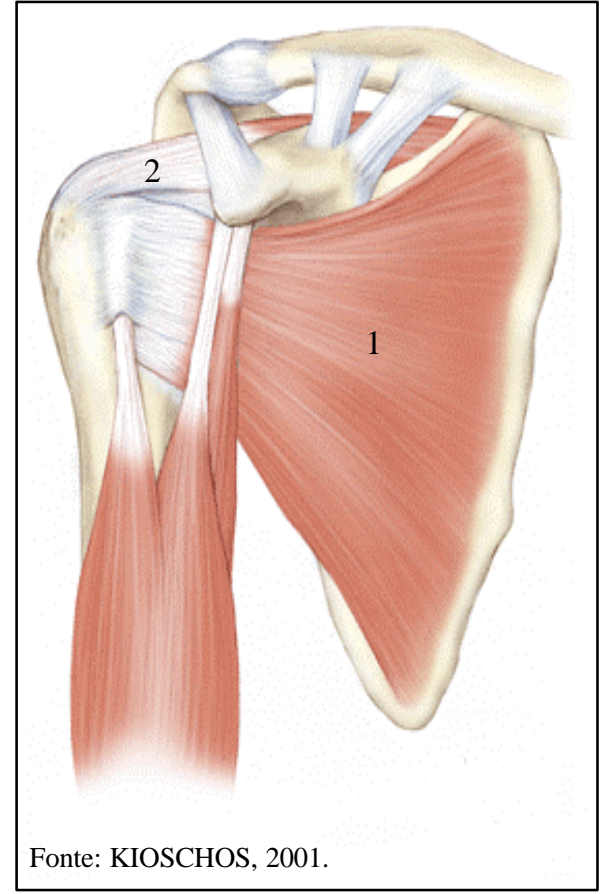

Figura 3- Vista anterior do manguito rotador apresentando o músculo subescapular (1) e supra-espinhoso (2).

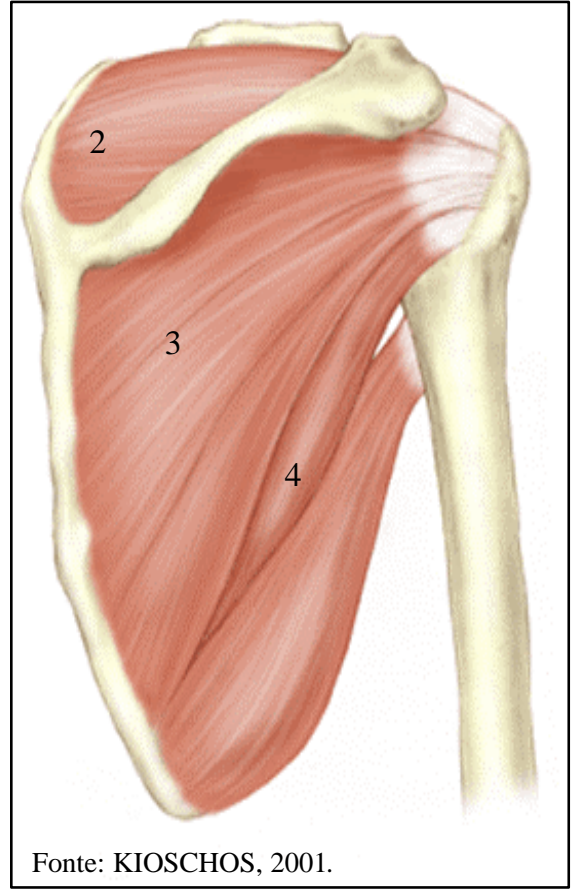

Figura 4- Vista posterior do manguito rotador, com supraespinhoso (2), infra-espinhoso (3) e redondo menor (4).

As estruturas do manguito rotador podem ser lesadas ao baterem contra os processos do acrômio ou coracóide, ou ainda contra o forte ligamento conector coracoacromial. Esta lesão ocorre com atividades que exigem a elevação do braço, como trabalhos acima da cabeça ou atividades esportivas que exigem arremesso, por exemplo (OVESEN \& NIELSEN, 1985).

Os principais músculos responsáveis pela rotação externa são o infraespinhoso e o redondo menor. São auxiliares no movimento de rotação externa, o bíceps braquial, a porção posterior do deltóide e o supra-espinhoso. Este último exerce papel importante na abdução do ombro.

A rotação interna tem como motor primário o músculo subescapular. Os músculos auxiliares são o peitoral maior e o grande dorsal. 
Os músculos supra-espinhoso e infra-espinhoso são inervados pelo nervo supraescapular. O redondo menor é suprido pelo nervo axilar. Embora o infraespinhoso e o redondo menor sejam supridos por dois nervos diferentes, eles geralmente são descritos juntos porque são estreitamente relacionados em localização e ação, e algumas vezes são inseparáveis. O subescapular é inervado por nervos subescapulares (ROCKWOOD \& MATSEN, 1990). As complicações relativas à inervação do manguito rotador geralmente envolvem o nervo supraescapular.

Movimentos repetitivos do ombro servem como mecanismo para induzir irritação do nervo. O sinal clínico mais evidente é a atrofia da fossa supra e infraespinhal, acompanhado de redução da força de rotação externa. A confirmação diagnóstica é feita por eletroneuromiografia (ANDRADE et al., 1993).

\subsection{ASPECTOS DA BIOMECÂNICA ESCAPULOUMERAL}

SMITH et al., (1997) relataram que durante a abdução do ombro, os movimentos conjugados entre a escápula, o úmero e a clavícula atendem a um ritmo controlado e equilibrado de ações musculares e articulares, o que permite a máxima eficiência funcional com o mínimo de agressões sobre as estruturas envolvidas no movimento. A escápula, mais especificamente a cavidade glenóidea, deve ser base de sustentação para a cabeça do úmero durante todo o ciclo de movimento, pois anormalidades associadas a restrições articulares gerando compensações nesse mecanismo, podem predispor a lesões por impacto das estruturas subacromiais.

POPPEN \& WALKER (1976) relataram que, nos primeiros 30 graus de abdução glenoumeral, a escápula permanece praticamente estabilizada sobre o gradil costal e a relação entre os movimentos da articulação glenoumeral e da articulação 
escapulotorácica é de 4,3: 1. Após os primeiros 30 graus de abdução do úmero, a escápula e a clavícula começam a se envolver no movimento predominante de rotação no sentido anti-horário da escápula. O eixo dessa rotação estende-se da articulação esternoclavicular até a base da espinha da escápula (ROCKWOOD \& MATSEN, 1990).

O resultado é um movimento predominante de rotação angular da escápula, sem nenhum deslocamento linear. O movimento é limitado a partir de 100 graus de abdução, com a tensão dos ligamentos costoclaviculares restringindo a mobilidade na articulação esternoclavicular. Nesse percurso do movimento, o vetor de força no sentido cranial, exercido pelo músculo deltóide sobre a cabeça do úmero, é contrabalançado pela ação depressora dos músculos que geram um vetor de força caudal à cabeça do úmero, ou seja, pelo músculo infra-espinhoso, subescapular e redondo menor que desempenham tal ação, devido à orientação oblíqua de suas fibras em relação ao úmero (MORRISON et al., 1997).

A entrada em tensão dos ligamentos coracoclaviculares obriga a clavícula a rodar dorsalmente, sem a qual a abdução estaria limitada a 120 graus (INMAN et al., 1944). O movimento escapular nessa angulação é, portanto, de rotação e deslocamento anterior (báscula lateral e abdução), numa combinação de movimento angular e linear, para permitir que a glenóide forneça uma base de sustentação viável e equilibrada para a cabeça do úmero no percurso do movimento global.

A relação de movimento entre a articulação glenoumeral e a articulação escapulotorácica varia de acordo com diferentes autores sendo de 2:1 para INMAN et al., (1944); 2,34: 1 para DUVALL (1955); 1,35:1 para FREEDMAN \& MUNRO (1966) e 1,25: 1 para POPPEN \& WALKER (1976). 
Todo esse conjunto de movimentos sincrônicos é conseguido, em grande parte, pela ação equilibrada dos rotadores do ombro.

Os músculos do manguito rotador desempenham três funções básicas segundo CRAIG (2000):

1.Potencializam as rotações da articulação glenoumeral, em decorrência da ação primária dos músculos infra-espinhoso, redondo menor e subescapular. A rotação lateral é imprescindível durante a abdução glenoumeral, pois libera a tuberosidade maior do úmero do atrito com o acrômio.

2.Estabilizam a dinâmica da articulação glenoumeral. A ação estabilizadora do manguito é fundamental para a mecânica normal do complexo do ombro, com ação centralizadora dos músculos subescapular e infra-espinhoso.

3.Proporcionam um compartimento fechado importante para a nutrição das superfícies articulares da cabeça umeral e cavidade glenóidea.

$\mathrm{O}$ autor relata ainda que o músculo supra-espinhoso parece proporcionar uma restrição estática à migração superior da cabeça do úmero. O músculo infraespinhoso, o redondo menor e o subescapular exercem ação primária na depressão da cabeça do úmero, em razão do sentido oblíquo de suas fibras em direção a esse osso, o que gera um vetor de força no sentido caudal sobre sua cabeça (force couple) evitando o deslizamento cranial da cabeça umeral pela ação do músculo deltóide, representado na FIGURA 5. 


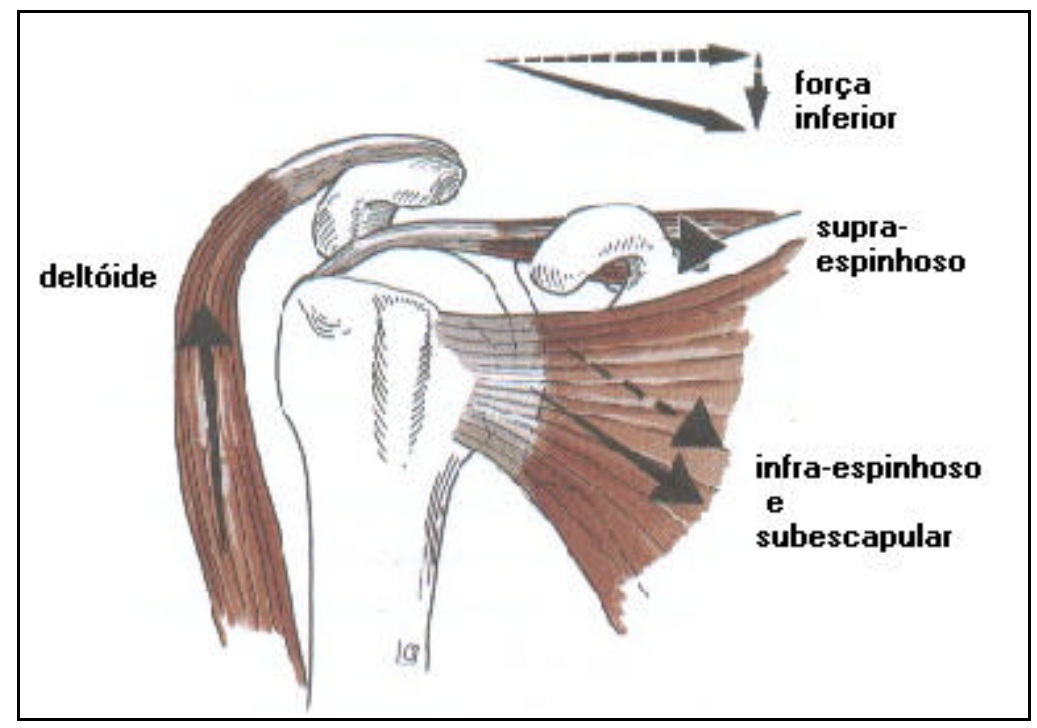

Figura 5- Mecanismo de force couple entre os músculos do manguito rotador e deltóide (Fonte: Souza, 2001).

Estudos eletromiográficos foram desenvolvidos com a finalidade de quantificar o nível de contração dos músculos do manguito rotador nas diversas funções da vida diária, e observou-se que a quantidade de fibras musculares ativadas variava consideravelmente de acordo com o posicionamento do braço, sendo um fator de empecilho na veracidade dos valores encontrados (McCANN et al., 1992).

Análises eletromiográficas dos rotadores foram realizadas a 60 graus e 180 graus de abdução, demonstrando ação efetiva do bíceps braquial, como coadjuvante na rotação externa do braço elevado (DAVID \& MAGAREY, 2000).

Diagnóstico por imagem também tem sido utilizado para determinar o nível de atuação e funções específicas do subescapular, redondo menor, supra-espinhoso e infra-espinhoso, a fim de identificar alterações pré e pós-esforço muscular (JAOVISIDHA \& JACOBSON, 1999).

NEER (1983), em seus estudos, sugeriu que a força de rotação externa aumenta e a de rotação interna diminui com a abdução progressiva do ombro. 


\subsection{DESEQUILÍBRIOS MUSCULARES DOS ROTADORES DO OMBRO}

O equilíbrio da cabeça umeral na cavidade glenóide é obtido por forças ativas dos rotadores do ombro.

O desequilíbrio de força dos rotadores pode gerar patologias do manguito que incluem tendinite, bursite subacromial, ruptura parcial ou total do manguito rotador e síndrome do impacto. Um fator importante na maioria dos casos é seu uso excessivo, especialmente em modalidades esportivas. Os sintomas variam de um pequeno desconforto a um enfraquecimento profundo do ombro e uma dor incapacitante grave (CANAVAN, 2001).

Mais recentemente CIULLO (1996) propôs que microtraumas repetidos levariam a uma atrofia do manguito, aumentando assim a migração superior da cabeça umeral durante a elevação do braço. O choque repetido da grande tuberosidade contra o arco coracoacromial acaba por formar esporões agravando assim o trauma tendinoso.

Essas e outras observações ainda deixam sem resposta se os esporões levam ao impacto ou se o impacto induz à formação dos esporões. A patologia do manguito rotador é um processo cíclico perpetuante como representado pelos autores MATSEN \& ARNTZ (1990), na FIGURA 6. 


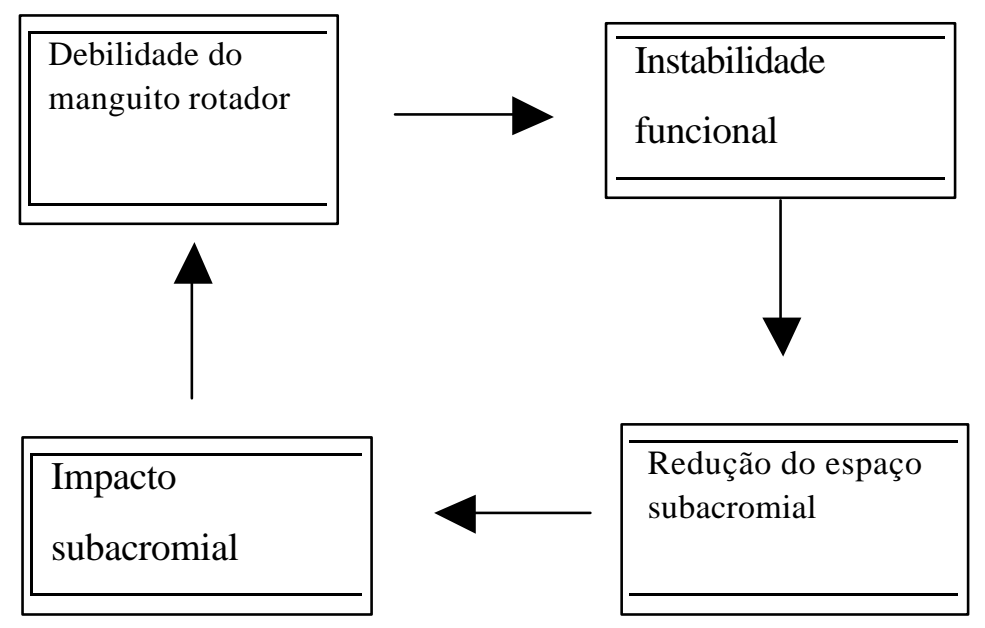

Figura 6 - Processo cíclico da patologia do manguito rotador (Fonte: Matsen e Arntz, 1990).

A importância da integridade no nível de força entre os músculos do manguito rotador também são primordiais no trabalho de equilíbrio posicional articular em indivíduos que apresentam lesão da cápsula articular (SAVOIE, 2000).

NORBEG \& FIELD (2000) enfatizaram que em reparos cirúrgicos do manguito rotador, prega-se a artroscopia, com a finalidade de lesar ao mínimo as fibras destes músculos, evitando desta forma instabilidades da junta.

A negligência às instabilidades mecânicas do ombro pode gerar problemas por vezes irreversíveis, como a capsulite adesiva do ombro ou ombro congelado, situação na qual o indivíduo perde a capacidade de mover a articulação tanto ativa como passivamente (BASTI, 1992).

PAYNE et al., (1997) realizaram um estudo biomecânico sobre a contribuição dos fatores estáticos e dinâmicos para o impacto subacromial. Dez ombros de cadáveres humanos frescos, com média de idade de 71 anos, variando de 56 a 86 anos foram testados. As espécies foram dissecadas e livres de tecido mole, 
exceto para o manguito rotador, deltóide, cabeça longa do bíceps e os ligamentos coracoacromial e glenoumerais. Neste estudo, os autores verificaram pressões acromiais foram aumentadas quando não foram aplicadas forças no manguito rotador. A força inferior do infra-espinhoso, redondo menor e subescapular foram necessárias para neutralizar uma força de cisalhamento superior produzida pelo deltóide e supra-espinhoso. Estes resultados foram obtidos através da colocação de um transdutor em miniatura com invasão mínima (inserido a $0,28 \mathrm{~mm}$ de profundidade e 2,6mm de diâmetro) no espaço subacromial.

A síndrome do impacto é uma entidade clínica que afeta 2 a $18 \%$ da população adulta. $\mathrm{O}$ primeiro estágio da síndrome, onde se encontra edema e hemorragia reversível nos tecidos do espaço subacromial, está presente em pacientes de até 25 anos de idade; o segundo consiste de fibrose e tendinite que afetam o manguito rotador de pacientes entre 25 e 40 anos; e o terceiro compreende esporões ósseos e rupturas do tendão entre indivíduos com mais de 40 anos (NEER, 1972).

Incidência antes de 35 anos se refere habitualmente aos desportos como natação, pólo aquático, beisebol, futebol americano ou ocupações que envolvem extensos movimentos com o braço acima da cabeça (JOBE \& PINK, 1993).

A síndrome do impacto afeta também populações especiais. Os atletas que competem em cadeiras de rodas, por exemplo, sofrem uma alta incidência. A incidência sobre os nadadores aparece por desequilíbrio muscular, com fraqueza relativa dos abdutores e rotadores externos (BURNHAM et al., 1993). 


\subsection{SISTEMAS DE AVALIAÇÃO DA FORÇA MUSCULAR}

Várias formas de se avaliar a força muscular de um indivíduo foram descritas na literatura e são utilizadas na prática clínica.

O termo força muscular é com freqüência usado para significar a habilidade de um músculo em produzir ou resistir a uma força. Este conceito pode ser relacionado com a habilidade de um músculo em vencer uma carga, tal como ocorre na contração com encurtamento; para manter uma carga como em uma contração estática ou para oferecer suporte para uma carga através de um alongamento muscular como na contração com alongamento. Podemos então classificar a contração muscular em isométrica (estática), contração concêntrica (de encurtamento do músculo) e excêntrica (de alongamento). Em situações normais, a força muscular ou a quantidade de força que um músculo pode produzir não pode ser medida diretamente. Para determinar a força muscular, mede-se a quantidade de resistência que o sistema de alavanca muscular pode vencer ou manter (MALONE et al., 2000).

Segundo o ponto de vista da física, força é a capacidade de um corpo alterar o seu estado de movimento ou repouso, criando uma aceleração ou deformação do mesmo. No âmbito desportivo a força traduz a capacidade da musculatura produzir tensão, ou contração muscular (HERTOHG et al., 1994).

Do ponto de vista fisiológico, a maior ou menor capacidade de produção de força estabelece uma relação direta com o número de pontes cruzadas de miosina que interagem com os filamentos de actina, com o número de sarcômeros, com o comprimento e o tipo de fibras musculares e com fatores inibidores ou facilitadores da atividade muscular (WEINECK, 1989). 
$\mathrm{O}$ arranjo das fibras de cada músculo determina a quantidade de força que o músculo pode produzir e o comprimento no qual os músculos podem se contrair. Os músculos freqüentemente agem juntos para obter uma força resultante com a magnitude e direção desejada. A distância em que o músculo se insere a partir do eixo articular determina o momento de força muscular, enquanto que o ângulo de tração muscular controla os componentes rotatórios da força (GOULD, 1993).

Vários dispositivos tentam acompanhar as mudanças nos fatores mecânicos da contração muscular. Estes dispositivos acomodam a resistência, mesclando a força aplicada e registrando a resistência em um marcador ou gráfico em toda a amplitude de movimento. Outros dispositivos proporcionam sistemas excêntricos ou sistemas de alavancas que variam a distância ao longo da amplitude de movimento, de modo que menos força muscular é necessária na área mais fraca. Todos esses dispositivos tentam prover um efeito de exercício ou uma medida indireta da força muscular (SHINZATO \& BATISTELA, 1996).

As provas de função muscular, utilizando exclusivamente a ação da gravidade, foram descritas pela primeira vez por Wright em 1912, e Lovett em 1916 (HISLOP \& MONTGOMERY, 1996).

O clínico que trabalha em reabilitação mede a força determinando, por exemplo, se o paciente é capaz de passar sem ajuda da posição sentada para a posição ortostática, ou então, mediante o exame manual da força muscular, por meio de um dinamômetro isocinético computadorizado ou dos testes de agilidade para medida da força funcional, podendo utilizar ainda um dinamômetro manual, exercícios de resistência progressiva e tensiômetros isométricos computadorizados (DAVIES, 1981). 
Como existem vários métodos de uso freqüente para a avaliação da força muscular, pode ocasionalmente haver confusão quando se trata de examinar ou avaliar esta força.

Podemos classificar o exame da função muscular em avaliação manual, avaliação com dinamometria isométrica e avaliação com dinamometria isocinética.

\section{Avaliação manual}

O exame manual da força muscular é um método freqüentemente usado no ambiente clínico para conhecer a força muscular. O método foi introduzido pelo Dr. Robert Lovett, baseado na ação da gravidade (ELLENBECKER \& DERSCHEID, 1988). Signe Brunnstrum e Marjorie Dennen criaram um sistema de graduação que avalia os movimentos e não a ação muscular propriamente dita. Elizabeth Kenny introduziu um método para registrar a capacidade funcional, a presença de espasmo e a falta de coordenação dos músculos afetados pela poliomielite (MALONE et al., 2000).

A avaliação manual da força muscular é um método barato, rápido, sempre disponível e que fornece dados relativamente confiáveis, sobretudo quando executado por um profissional experiente (SHINZATO \& BATISTELLA, 1996).

Este método de avaliação foi extensivamente estudado e padronizado do ponto de vista semiológico. O aspecto qualitativo é abordado, porém, do ponto de vista quantitativo esse sistema se mostra limitado.

Segundo os testes de força descritos por Daniels \& Worthingham (1986), a função muscular avaliada por processos manuais é graduada numericamente de 0 (zero), que corresponde a ausência de atividade, a 5 (cinco), que representa uma 
resposta normal a prova. $\mathrm{O}$ teste muscular manual irá auxiliar na percepção de déficit muscular grosseiro, sendo pouco fidedigno e muito subjetivo. A FIGURA 7 apresenta a classificação da força muscular avaliada com o teste manual.

\begin{tabular}{|c|c|}
\hline \multicolumn{2}{|c|}{ Classificação da força muscular avaliada com teste manual } \\
\hline Função & Sinal Clínico \\
\hline 0 & Paralisia total \\
\hline 1 & Contração visível ou palpável \\
\hline 2 & Movimento ativo, amplitude normal, força de gravidade compensada. \\
\hline 3 & Movimento ativo, amplitude normal, contra gravidade, sem carga. \\
\hline 4 & Movimento ativo, amplitude normal, contra carga moderada. \\
\hline 5 & Movimento ativo, amplitude normal, contra grande resistência (normal). \\
\hline
\end{tabular}

Fonte: Hislop \& Montggomery (1996).

Figura 7 - Padrão semiológico para o teste de força muscular manual.

\section{Avaliação com dinamometria isométrica}

É um método que permite avaliar a maioria dos grupos musculares. A utilização de um tensiômetro ou de um dinamômetro isométrico irá permitir uma avaliação mais precisa da força (GOULD, 1993).

A avaliação instrumental da função muscular iniciou-se com os dinamômetros, que caracterizam o método de avaliação como quantitativo, pois os aparelhos atribuem um valor numérico ao teste (PEARN, 1978).

A dinamometria refere-se a todo tipo de processo que tem em vista a medição de forças, bem como, a medição da distribuição de pressões (ADRIAN \& COOPER, 1995; AMADIO, 1996). O dinamômetro é um tipo de equipamento que mensura o comportamento da carga ou tensão por deformação das estruturas (FENOLL, 2002). 
Contrações musculares isométricas indicam a força muscular na posição articular testada. A força muscular através da amplitude de movimento pode ser testada em vários ângulos específicos para se obter um parâmetro da força muscular ao longo da amplitude. Um tensiômetro ou dinamômetro é o método mais comum usado para testar a força muscular. Ocasionalmente pode ser mantido um peso livre para obter a determinação máxima da força muscular estática. A força real da contração muscular pode ser estimada usando-se cálculos matemáticos (MALONE et al., 2000).

No treinamento de força estática ou isométrica, o trabalho físico é igual a zero, pois o produto da força pelo caminho é igual a zero. Neste método não ocorre uma contração visível, como no treinamento dinâmico, mas sim um maior desenvolvimento da tensão. A força estática é aquela tensão que um músculo ou grupo muscular pode exercer arbitrariamente, numa determinada posição, contra uma resistência fixada e o tempo de tensão ideal para avaliar a força muscular é estimado entre 6 e 8 segundos(WEINECK, 2000).

Recentemente os dinamômetros manuais adquiriram mais popularidade. Em sua maioria, estas unidades funcionam como medidores de compressão e/ou de tração.

\section{Avaliação com dinamometria isocinética}

O conceito de exercício isocinético foi desenvolvido por James Perrine e introduzido na literatura científica em 1967 por Hislop e Perrine. Foram então desenvolvidos os equipamentos que permitem a determinação dos momentos articulares, tendo como característica principal a manutenção de uma velocidade angular constante na articulação avaliada (em graus por segundo) para qualquer nível 
de força exercido. Os dinamômetros isocinéticos foram progressivamente aprimorados do ponto de vista de confiabilidade dos dados e da facilidade operacional dos equipamentos, permitindo também o registro e o estudo de outras variáveis do desempenho muscular como trabalho, potência, velocidade, resistência e fadiga (SHINZATO \& BATISTELLA, 1996).

A velocidade depende da tecnologia do equipamento, variando entre 1 grau por segundo e 500 graus por segundo. Os exercícios isocinéticos encontram amplo emprego na avaliação do desempenho muscular, assim como para fins de reabilitação e documentação científica objetiva (MALONE et al., 2000).

Esta característica inerente aos dinamômetros isocinéticos permite a sobrecarga de um músculo em $100 \%$ de sua capacidade máxima em toda a amplitude de movimento. A gama de velocidades angulares desenvolvidas pelos dinamômetros isocinéticos permite uma avaliação funcional, porém ainda não se aproxima da velocidade angular real observada nas atividades corriqueiras como, por exemplo, 300 a 700 graus por segundo para a articulação do joelho durante a corrida, e atividades esportivas específicas como, por exemplo, 5.000 graus por segundo na articulação glenoumeral durante o arremesso no beisebol, de acordo com os estudos de GOULD (1993).

Dentre as articulações do corpo, o complexo do ombro se mostra como a região que mais depende dos níveis normais de força muscular para preservação de sua estrutura. 


\subsubsection{Avaliação da força muscular do ombro}

Alguns trabalhos relacionados à avaliação da força muscular do ombro têm sido relatados na literatura.

DAVID \& MAGAREY (2000) utilizaram análise eletromiográfica combinada com avaliação isocinética da rotação do ombro em 15 sujeitos (30 ombros) jovens, assintomáticos do sexo masculino.

Os autores relataram que a avaliação isocinética da rotação do ombro, não envolve movimentos puros.

Instruções para o uso do dinamômetro isocinético (CYBEX DIVISION OF LUMEX RONKONKOMA, NEW YORK), recomendam testar a força de rotação do ombro no plano coronal ou sagital, com o úmero a 90 graus de abdução ou flexão (KUHLMAN et al., 1992).

CAHALAN et al., (1989) avaliaram a força muscular de abdução, adução, flexão, extensão, rotação interna e externa de 50 sujeitos (26 homens e 24 mulheres) com idades entre 21 e 40 anos. Neste estudo, os autores utilizaram a avaliação isocinética através do Cybex II em diferentes velocidades, além da avaliação isométrica. Como resultado, os autores encontraram (1) valores maiores de torque isométrico se comparado a torques isocinéticos em todos os planos, com exceção da extensão do ombro (homens e mulheres) e adução do ombro (em homens); (2) os picos de torque diminuíram quando aumentavam a velocidade do movimento isocinético; (3) a força de rotação interna foi maior que a força de rotação externa; (4) homens foram significativamente mais forte que as mulheres para todos os movimentos testados. 
IVEY et al., (1985) mediram os torques isocinéticos em indivíduos normais a 60 e 180 graus por segundo. As razões máximas de torques foram observadas como sendo de 3:2 para os rotadores internos e externos. Não houve nenhuma diferença significativa entre os lados dominante e não dominante. Estudos isocinéticos em atletas de esportes de lançamento (arremesso) mostram razões ligeiramente diferentes, particularmente a altas velocidades, e algumas diferenças importantes entre os lados dominantes e não dominantes.

BACKMAN et al., (1995) avaliaram a força isométrica de vários grupos musculares (flexores do cotovelo, extensores do joelho, dorso-flexores do tornozelo, abdutores do ombro, flexores do quadril entre outros) em 63 mulheres e 65 homens, com idade entre 17 e 70 anos, utilizando dinamômetro portátil com capacidade para 60 kgf.

GODINHO et al., (1994) avaliaram a força muscular durante a elevação do ombro no plano da escápula em pacientes previamente submetidos à cirurgia do ombro. A medida quantitativa da força foi feita através da utilização de uma balança de uso doméstico, com carga máxima de $20 \mathrm{~kg}$. Segundo os autores, um método simples de avaliação da força, no caso isométrica, mas que produziu resultados semelhantes àqueles realizados a título experimental.

Nos estudos de OTIS et al., (1990) a medida do torque dos músculos do ombro foi obtida de 36 homens adultos jovens, durante flexão, abdução, rotação interna e externa do ombro. $\mathrm{O}$ torque foi medido usando dinamômetro isocinético Cybex II. 
Rotação interna e externa foram testadas com o indivíduo em supino, sobre uma mesa de teste; o úmero foi abduzido a 90 graus e o cotovelo fletido a 90 graus. O tronco foi estabilizado com faixas durante a realização das medidas.

GREENFIELD et al., (1990) avaliaram a força isométrica de rotação do ombro no plano frontal e no plano da escápula, em 20 indivíduos, usando o Merac ${ }^{\circledR}$ (Universal Gym Equipament, Inc., Cedar Rapids, 1A).

O propósito do estudo destes autores foi, comparar a força dos rotadores do ombro no plano da escápula (entre 30 a 45 graus anteriores ao plano frontal) e no plano frontal. A conclusão deste trabalho indica diferença significativa para os torques de rotação externa, que são maiores no plano da escápula que no plano frontal. Porém não houve diferença significativa para os torques de rotação interna.

HUGHES et al., (1999) investigaram a relação entre idade e o desempenho de força isométrica em ombros normais. Neste estudo o equipamento Cybex II (dinamômetro isocinético) foi utilizado para avaliar a força isométrica de flexão, extensão, abdução, adução, rotação interna e externa do ombro de 120 indivíduos (60 mulheres e 60 homens) com idades entre 20 e 78 anos.

Os resultados mostraram que as idades foram negativamente associadas com todas as medidas de força, e homens foram mais fortes que mulheres quando controlados por idade e carga.

MURRAY et al., (1985) utilizaram um equipamento mecânico adaptado a uma cadeira. Faixas foram fixadas nos membros superiores dos indivíduos e ligadas a um medidor de força através de uma corda de nylon. A resistência era fornecida por estruturas estacionárias de metal. Força muscular e amplitude de movimento 
foram avaliadas em 40 indivíduos saudáveis (20 homens e 20 milheres) com idades entre 25 e 36 anos e entre 55 e 66 anos de idade.

ANDRADE et al., (1996) fizeram um estudo comparativo do pico de força de rotação interna e externa do ombro, comparando o membro dominante $x$ não dominante em 48 atletas de voleibol. Para medição da força muscular, foi utilizado um dinamômetro eletrônico isométrico (Jackson Evaluation System Model 32528/ Lafayette Instrument Co.). Neste equipamento, uma faixa elástica, presa por um gancho é ligada ao dinamômetro. O indivíduo foi avaliado em ortostatismo, com braço ao lado do corpo. Diferença significativa foi encontrada para valores de rotação interna, mas não para rotação externa, sendo o braço dominante mais forte.

KUHLMAN et al., (1992) realizaram medidas de força isométrica, comparada à força isocinética dos rotadores externos e abdutores do ombro no plano da escápula (30 a 45 graus anteriores ao plano frontal). Para testar a força de rotação externa, o indivíduo foi posicionado em supino e estabilizado por almofadas, com o ombro abduzido a 45 graus. Os autores realizaram ainda, bloqueio do nervo supraescapular e confirmaram a inatividade muscular do supra-espinhoso e infraespinhoso por eletromiografia.

Os resultados deste estudo foram: (1) maior torque em cada grupo foi obtido com o teste isométrico, comparado aos resultados de torque isocinético; (2) testes isométricos depois do bloqueio do nervo supraescapular mostraram que o supraespinhoso e infra-espinhoso contribuíram com aproximadamente $50 \%$ da força de abdução e maior proporção (aproximadamente 75\%) com a força de rotação externa. 


\subsection{OBJETIVO}

O objetivo deste trabalho foi desenvolver um aparelho capaz de mensurar de forma eficaz a força isométrica dos rotadores do ombro, utilizável tanto na padronização dos níveis normais de força destes músculos quanto na identificação de distúrbios funcionais dos mesmos. 
2. MATERIAL E MÉTODO 
Esse trabalho foi realizado no Laboratório de Bioengenharia da Faculdade de Medicina de Ribeirão Preto da Universidade de São Paulo.

O projeto do aparelho para avaliar o torque isométrico dos rotadores do ombro foi desenvolvido em etapas distintas. Inicialmente foi planejado o protótipo do aparelho, que denominamos Plataforma Torsional do Ombro ou PTO. Um estudo das variações antropométricas foi utilizado para auxiliar no dimensionamento do aparelho.

Após a definição do modelo e padronização das medidas, o PTO foi construído e utilizado na avaliação bilateral dos ombros de indivíduos normais, a fim de verificar sua adaptabilidade e eficiência.

Com a finalidade de facilitar o manuseio do aparelho, algumas mudanças foram feitas no protótipo, dando origem a sua versão final. Esta versão também foi submetida aos testes de adaptabilidade e eficiência.

\subsection{PLANEJAMENTO DO PROTÓTIPO}

\subsubsection{Definição do modelo}

A definição do modelo do PTO foi baseada no posicionamento desejado para a realização dos testes de força de rotação interna e externa do ombro.

Optamos por avaliar a força dos rotadores do ombro com o membro superior ao lado do corpo e com apoio para o antebraço a fim de minimizar a influência de grupos musculares acessórios. Este posicionamento não coloca os tendões do 
rotadores do ombro em condição de impacto no espaço subacromial permitindo sua utilização em indivíduos com comprometimento do manguito rotador.

Decidimos pela avaliação do ombro no plano da escápula (30 a 45 graus anteriores ao plano frontal) com o objetivo de não influenciar o torque produzido pelos rotadores externos, conforme verificado em estudos anteriores.

Para atenuar os efeitos das contrações musculares do membro inferior, quadril e tronco sobre o desempenho de força dos rotadores do ombro, resolvemos que a avaliação da força muscular seria realizada a partir da posição sentada.

$\mathrm{O}$ atendimento a estes quesitos resultou no desenvolvimento de um protótipo para a avaliação do torque isométrico dos 1otadores do ombro que permite avaliar o desempenho destes músculos em toda a amplitude de rotação do ombro.

\subsubsection{Dimensionamento do protótipo}

O dimensionamento dos componentes do protótipo foi definido a partir de um estudo das variações antropométricas. Os limites de estatura utilizados para análise das dimensões do PTO localizaram-se entre 1,40m (valor mínimo) e 2,10m (valor máximo).

O comprimento dos segmentos do corpo e demais medidas necessárias ao ajuste do PTO foram obtidos através de uma fração da altura corporal total $(\mathrm{H})$, como representado na FIGURA 8. 


\begin{tabular}{|l|c|c|c|}
\hline \multicolumn{1}{|c|}{ Medidas } & $\begin{array}{c}\text { Fração da } \\
\text { altura }\end{array}$ & $\begin{array}{c}\text { Mínimo } \\
\text { (indivíduo com } \\
1,40 \mathrm{~m} \mathrm{de} \\
\text { altura) }\end{array}$ & $\begin{array}{c}\text { Máximo (indivíduo } \\
\text { com 2,10m de } \\
\text { altura) }\end{array}$ \\
\hline $\begin{array}{l}\text { Comprimento do braço (do acrômio ao } \\
\text { epicôndilo lateral do úmero) }\end{array}$ & $0,186 \mathrm{H}$ & $26,04 \mathrm{~cm}$ & $39,06 \mathrm{~cm}$ \\
\hline $\begin{array}{l}\text { Comprimento do antebraço (do olecrano ao } \\
\text { processo estilóide da ulna) }\end{array}$ & $0,146 \mathrm{H}$ & $20,44 \mathrm{~cm}$ & $30,66 \mathrm{~cm}$ \\
\hline $\begin{array}{l}\text { Comprimento da mão (da prega do punho à } \\
\text { falange distal do dedo médio) }\end{array}$ & $0,108 \mathrm{H}$ & $15,12 \mathrm{~cm}$ & $22,68 \mathrm{~cm}$ \\
\hline $\begin{array}{l}\text { Distância do joelho ao solo } \\
\text { Distância do cotovelo ao solo (indivíduo } \\
\text { sentado, cotovelo fletido a 90 graus). }\end{array}$ & $0,430 \mathrm{H}$ & $60,20 \mathrm{~cm}$ & $59,85 \mathrm{~cm}$ \\
\hline $\begin{array}{l}\text { Largura da cintura escapular (distância entre a } \\
\text { articulação glenoumeral direita e esquerda) }\end{array}$ & $0,259 \mathrm{H}$ & $36,90 \mathrm{~cm}$ & $90,30 \mathrm{~cm}$ \\
\hline
\end{tabular}

Fonte: Winter, 1990.

FIGURA 8-Medidas utilizadas no dimensionamento do PTO

\subsubsection{Projeto do PTO}

Foram feitos alguns desenhos esquemáticos dos componentes do aparelho que, progressivamente, foram adquirindo as características necessárias para atender os objetivos propostos neste trabalho.

Os materiais para a confecção dos componentes do protótipo foram obtidos visando boa resistência, facilidade de manuseio e baixo custo. Uma cadeira foi adaptada para acomodar esses componentes.

A FIGURA 9 apresenta o desenho esquemático do protótipo. 


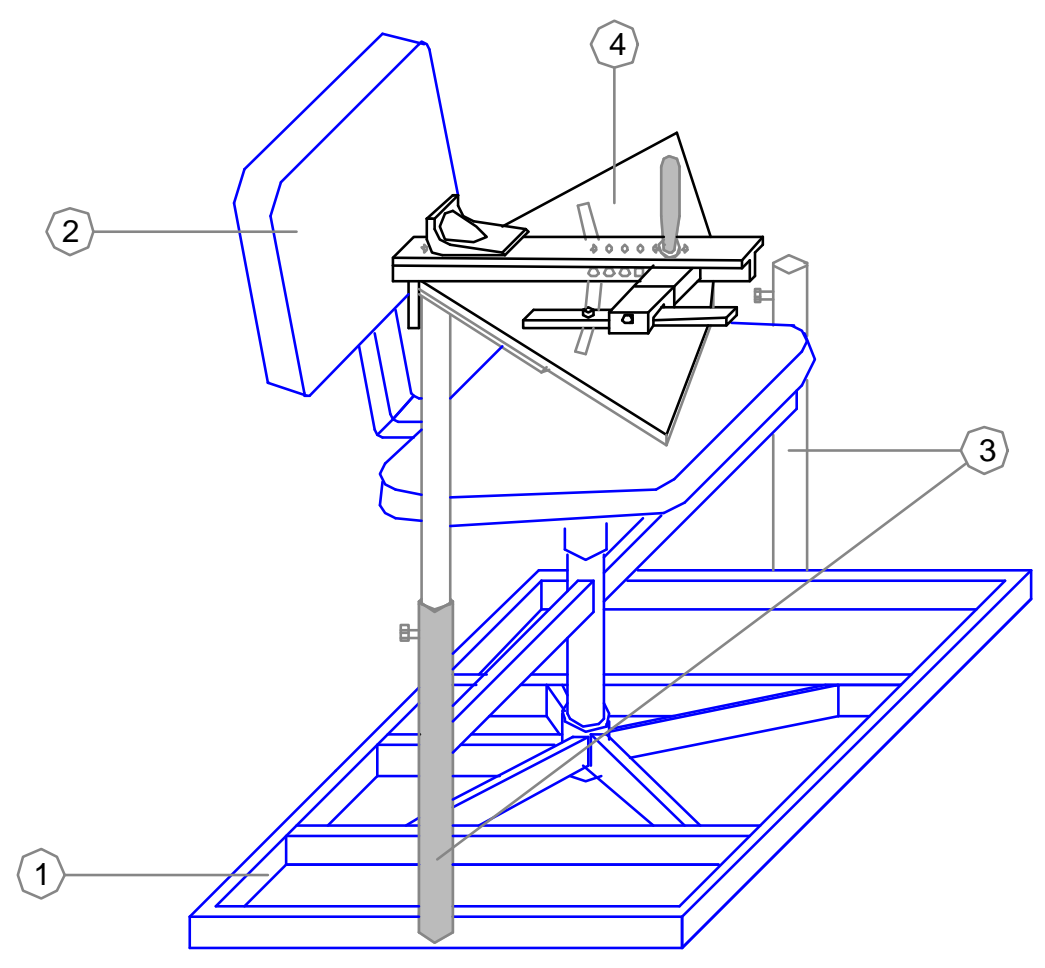

FIGURA 9 - Desenho esquemático do protótipo: 1) base de sustentação; 2) cadeira adaptada; 3) tubos telescopáveis e 4) plataforma de medição da força de rotação do ombro.

\subsection{CONSTRUÇÃO DO PROTÓTIPO}

Os componentes do protótipo foram confeccionados na Oficina de Precisão da Prefeitura do Campus da USP de Ribeirão Preto.

\subsubsection{Base de Sustentação}

Uma base de sustentação formada por barras retangulares em "metalon" com medida total de $650 \mathrm{~mm}$ x $650 \mathrm{~mm}$ foi confeccionada para fornecer um amplo suporte ao PTO.

No centro desta base de sustentação foi fixada uma cadeira especialmente adaptada, da marca STN 14 Stilo FL/4004, que possui ajuste para altura do assento 
$(100 \mathrm{~mm})$ e altura do encosto $(75 \mathrm{~mm})$.

Nas laterais foram fxados dois tubos em aço com comprimento de $450 \mathrm{~mm}$, a uma distância de $150 \mathrm{~mm}$ anterior ao plano do encosto da cadeira para que, através de um sistema de tubos telescopáveis, uma plataforma de medição da força de rotação do ombro pudesse ser acoplada bilateralmente.

A distância entre o plano do encosto da cadeira e os tubos de aço foi planejada para colocar o apoio do membro superior no plano da escápula (30 a 45 graus anteriores ao plano frontal). A FIGURA 10 apresenta o protótipo do aparelho desenvolvido para avaliar a força muscular isométrica dos rotadores do ombro.

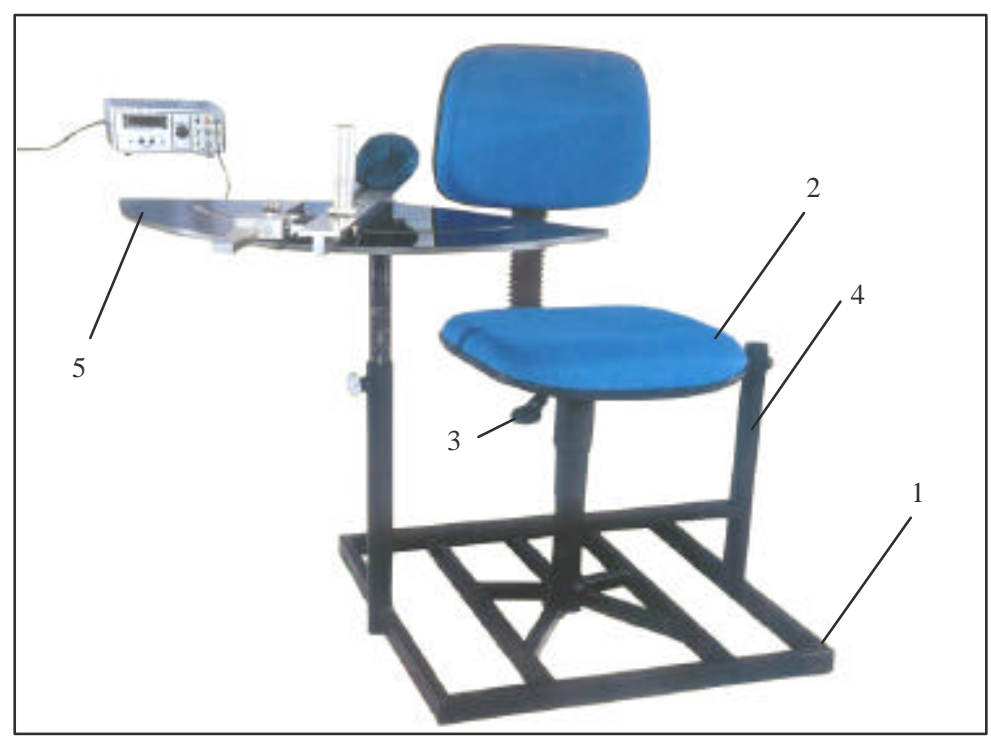

FIGURA 10 - Protótipo do aparelho desenvolvido para avaliar a força muscular isométrica dos rotadores do ombro: 1) base de sustentação; 2) cadeira adaptada; 3) ajuste de altura; 4) tubos telescopáveis e 5) plataforma de medição da força de rotação do ombro. 


\subsubsection{Plataforma de medição da força de rotação do ombro}

Uma superfície em acrílico de formato "setor circular", com $10 \mathrm{~mm}$ de espessura, sustentada por barras de ferro em suas extremidades inferiores foi conectada em sua porção proximal a um tubo de aço. Através deste tubo a superfície em acrílico era acoplada à cadeira. A altura do tubo era ajustável por parafuso.

Sobre a superfície em acrílico foram fixados os apoios para o antebraço e cotovelo, uma célula de carga e um manípulo para colocação da mão.

Uma haste em alumínio foi utilizada para fornecer apoio ao bordo ulnar do antebraço.

Esta haste, denominada haste de apoio do antebraço, foi confeccionada em alumínio em formato "T" e articulada ao acrílico por um parafuso do tipo "rosca sem fim" que permitia a movimentação da haste na angulação desejada.

Um apoio de cotovelo confeccionado em plástico termomoldável, revestido com espuma e tecido foi acoplado à porção proximal de haste de apoio do antebraço por meio de parafuso.

$\mathrm{Na}$ porção distal da haste de apoio do antebraço foram feitos 7 (sete) furos com distância de $20 \mathrm{~mm}$ entre eles para receber um manípulo.

O manípulo, também confeccionado em alumínio, possui $100 \mathrm{~mm}$ de altura e $30 \mathrm{~mm}$ de diâmetro. Em sua porção inferior, um prolongamento em rosca permitia seu encaixe sobre os furos da haste de apoio do antebraço. Assim, até $140 \mathrm{~mm}$ de variação no comprimento do antebraço podia ser acompanhada pela mudança na posição do manípulo.

Uma abertura feita na superfície em acrílico possibilitava a fixação de uma outra haste, denominada haste de fixação da célula de carga. Esta abertura permitia 
ainda a mudança na angulação de rotação do instrumento de medida e das hastes do PTO. A plataforma de medição da força dos rotadores do ombro é visualizada na FIGURA 11.

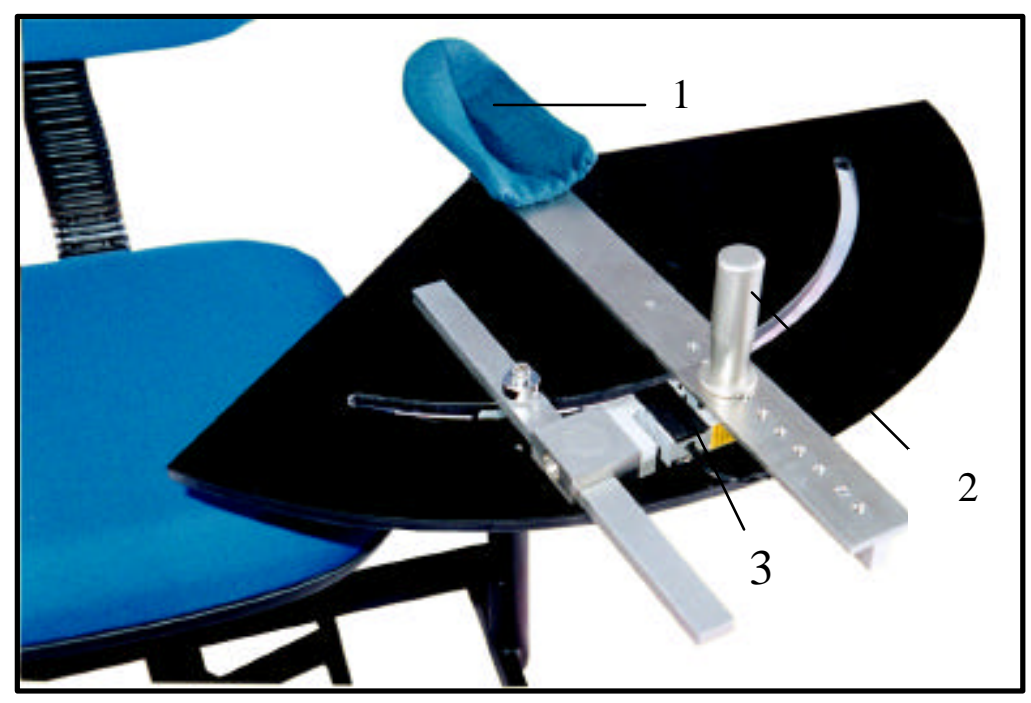

FIGURA 11 - Vista superior da plataforma sobre a qual os testes de força muscular foram realizados: 1) apoio de cotovelo; 2) manípulo para fixação da mão e 3) célula de carga.

\subsubsection{Fixação do instrumento de medida}

O instrumento de medida utilizado no protótipo foi uma célula de carga. As células de carga são dinamômetros destinados a medição de esforços de tração e/ou compressão estáticos ou dinâmicos. Nesse trabalho, a célula de carga foi considerada como um instrumento de medida indireta da força de rotação isométrica do ombro, uma vez que a mesma não é capaz de avaliar, de forma direta, o esforço mecânico de torção ou rotação.

$\mathrm{Na}$ porção inferior da haste de apoio do antebraço foram feitos furos, através dos quais a célula de carga da marca $\mathrm{Kratos}^{\circledR}$, com capacidade para medir até 200kgf 
podia ser parafusada em um dos lados.

No outro lado, a célula de carga se prendia a um suporte quadrado em alumínio, denominado suporte quadrado para fixação da célula de carga.

Este suporte quadrado foi confeccionado com uma abertura lateral que permitia seu deslizamento, juntamente com a célula de carga, ao longo da haste de fixação da célula de carga.

A haste de fixação da célula de carga, confeccionada em alumínio "chato", possuía um comprimento de $370 \mathrm{~mm}$ e era presa a abertura feita no acrílico por meio de um parafuso "Allen" ligado a uma porca fixa com pino guia.

Desta maneira, a variação no posicionamento do manípulo localizado na porção superior da haste de apoio do antebraço podia ser acompanhada pela variação no posicionamento da célula de carga localizada na porção inferior da haste de apoio do antebraço, permitindo o alinhamento da célula de carga ao centro de aplicação da força (FIGURA 12).

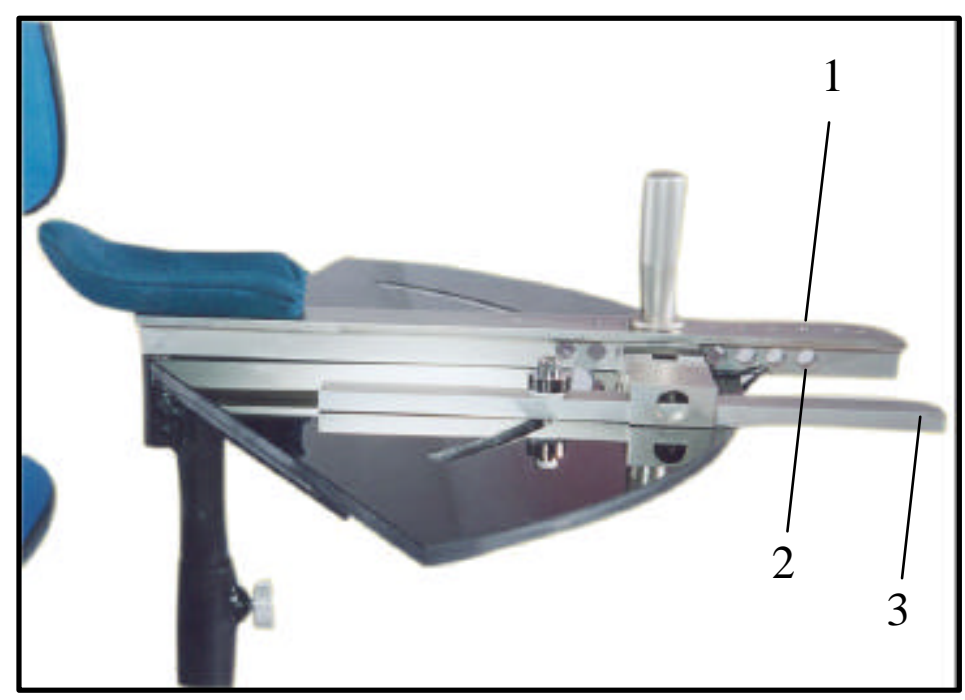

FIGURA 12 - Vista lateral do PTO: 1) furos para o posicionamento do manípulo; 2) furos para o alinhamento da célula de carga e 3) haste de fixação da célula de carga. 


\subsubsection{Leitura da força aplicada e calibração do PTO}

O torque obtido pelos testes de rotação interna e externa do ombro era composto pelo produto do braço de alavanca (distância do eixo de rotação da articulação do ombro até o manípulo) e a força aplicada pelo indivíduo, registrada pela célula de carga $\operatorname{Kratos}^{\circledast}$. A célula de carga fixada foi calibrada utilizando uma ponte de extensometria da marca Sodmex ${ }^{\circledast}$. Esta ponte de extensometria foi utilizada para a leitura da força aplicada.

Para calibração do PTO foram utilizadas massas aferidas e o fator de correção obtido foi o seguinte: para cada 20 (vinte) unidades registradas pela ponte de extensometria o valor correspondia a $1 \mathrm{kgf}$ exercida pelo indivíduo.

\subsection{TESTES DE EFICIÊNCIA E ADAPTABILIDADE DO PROTÓTIPO EM OMBROS NORMAIS}

Para verificar a eficiência e adaptabilidade do PTO, 10 (dez) indivíduos voluntários, saudáveis, de ambos os sexos e estatura variável foram submetidos a esforços isométricos de rotação do ombro em várias angulações e bilateralmente.

A postura de cada sujeito durante o procedimento do teste da força muscular isométrica dos rotadores do ombro foi a seguinte: (1) sentado com tronco ereto apoiado no encosto da cadeira; (2) braço abduzido a cerca de 10 graus; (3) cotovelo apoiado a 90 graus de fexão; (4) antebraço em posição neutra; (5) mão fixada ao manípulo; (6) ombro no plano da escápula, ou seja, 30 a 45 graus anteriores ao plano frontal. Os indivíduos foram orientados sobre as posturas compensatórias 
indesejáveis. Um goniômetro e uma fita métrica auxiliaram o processo de avaliação.

Cada sujeito foi submetido aos testes bilateralmente. A ordem do lado a ser testado foi aleatória. Todos os sujeitos foram orientados a realizar dois esforços submáximos em cada posição, antes da medida definitiva da força, com o objetivo de adaptação ao teste. Estes voluntários foram verbalmente encorajados a manter a contração por 6 (seis) segundos e o esforço máximo foi enfatizado.

O intervalo entre testes adaptativos $e$ testes definitivos foram de aproximadamente 3 (três) minutos. A finalidade do intervalo entre teste adaptativo e teste definitivo era atenuar o efeito do aprendizado motor e da facilitação neuromuscular.

Os parâmetros avaliados foram: (1) adaptação do aparelho às variações antropométricas dos indivíduos; (2) eficácia do aparelho na avaliação da força muscular de rotação do ombro e (3) nível de tolerância dos indivíduos durante os testes.

As FIGURAS 13 e 14 mostram diferentes angulações de rotação permitidas pelo PTO.

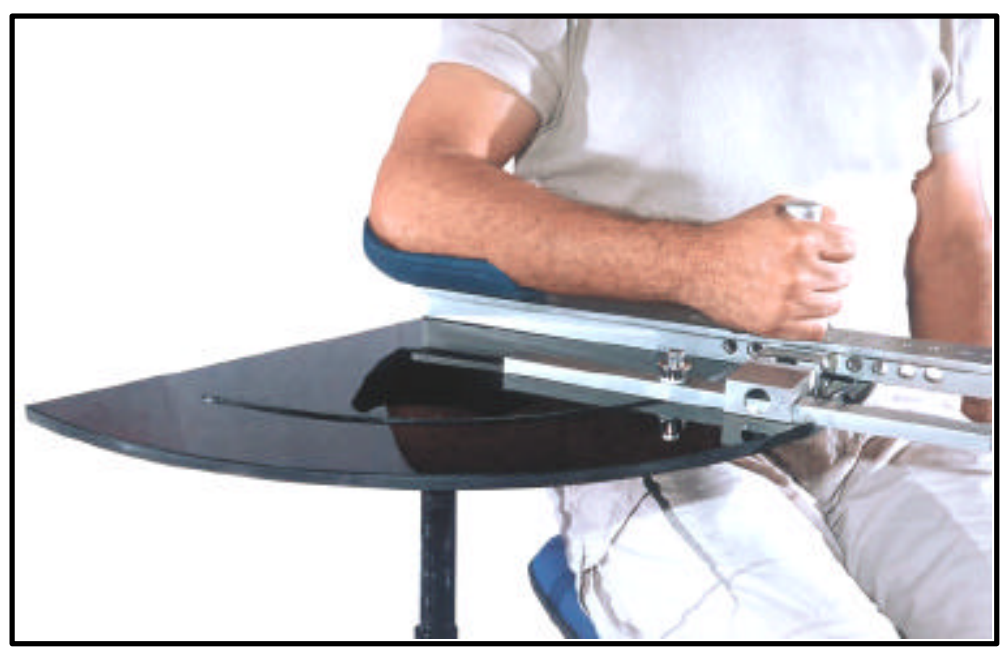

FIGURA 13 - Exemplo de utilização do PTO em angulação de rotação interna do ombro. 


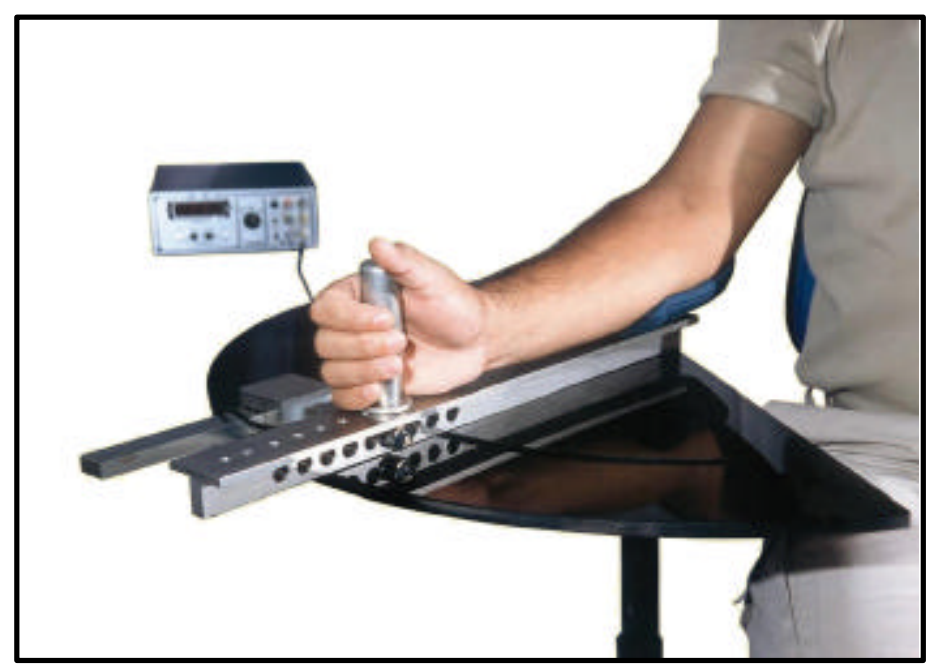

FIGURA 14 - Exemplo de utilização do PTO em angulação de rotação externa do ombro.

\subsection{VERSÃO FINAL DO APARELHO}

Durante os testes de eficiência e adaptabilidade do protótipo, foi observado que algumas mudanças poderiam facilitar o manuseio do PTO. Estas mudanças deram origem a sua versão final.

Serão comentadas neste item, as alterações feitas a partir do protótipo anteriormente descrito.

\subsubsection{Instrumento de medida}

A principal alteração a partir do protótipo foi a substituição do instrumento de medida indireta (célula de carga) por um instrumento de medida direta, neste caso, um torquímetro.

O torquímetro foi dimensionado de acordo com a Teoria da Resistência dos Materiais para suportar até $100 \mathrm{Nm}$ e confeccionado a partir de um cilindro de aço 
inoxidável. O princípio de medida deste instrumento baseia-se na deformação mecânica de um eixo equipado com extensômetros elétricos interligados em ponte completa ou ponte de "Wheatstone".

Os extensômetros elétricos, mais conhecidos pela nomenclatura inglesa "strain gauges", consistem de um conjunto de filamentos metálicos que transformam a energia mecânica (energia de entrada) em um sinal elétrico de saída.

Nesse trabalho, a energia mecânica avaliada é do tipo torsional estática, entretanto, estes instrumentos medem tanto torque estático quanto dinâmico.

A porção superior do torquímetro foi acoplada à haste de apoio do antebraço. Em sua porção central, usinada de forma a atender a capacidade de medição desejada, foram colados os "strain gauges" ou extensômetros elétricos. Um tubo de alumínio foi utilizado para proteger as ligações elétricas. Inferiormente, três furos permitem a fixação do torquímetro a um suporte feito no tubo telescopável de sustentação da plataforma de força, através de parafusos (FIGURA 15).

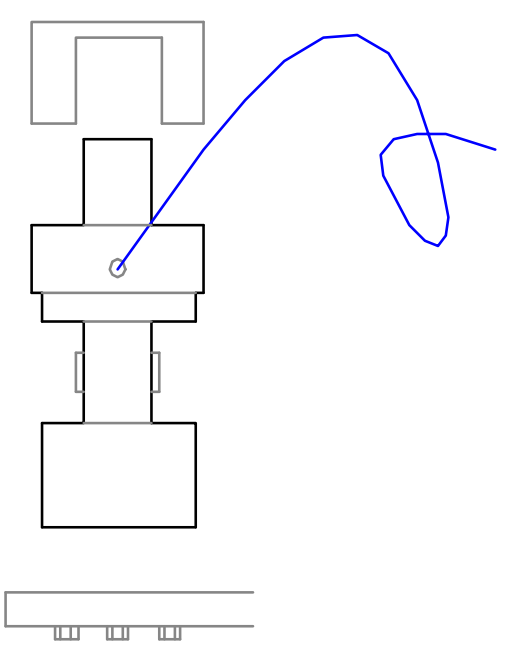

FIGURA 15 - Desenho esquemático do torquímetro. 


\subsubsection{Calibração do torquímetro}

O torquímetro é ligado a uma ponte de extensometria utilizada para leitura do torque aplicado. A ponte de extensometria, ou instrumento de leitura digital para transdutores, permite a medição de parâmetros físicos como esforços aplicados ou microdeformações por meio dos extensômetros elétricos. Com a utilização da ponte de extensometria e massas aferidas o aparelho foi devidamente calibrado.

Foram utilizadas 25 (vinte e cinco) massas aferidas de $1 \mathrm{~kg}$ com um braço de alavanca de $0,5 \mathrm{~m}$ e as leituras foram visualizadas na ponte de extensometria ou indicador digital. $\mathrm{O}$ gráfico de calibração do torquímetro (Torque $\mathrm{x}$ Indicador) demonstrou que até $120 \mathrm{Nm}$ a calibração era linear. A curva foi determinada pelo Método dos Mínimos Quadrados com o Coeficiente de Correlação $R^{2}=0,99994$ (FIGURA 16).

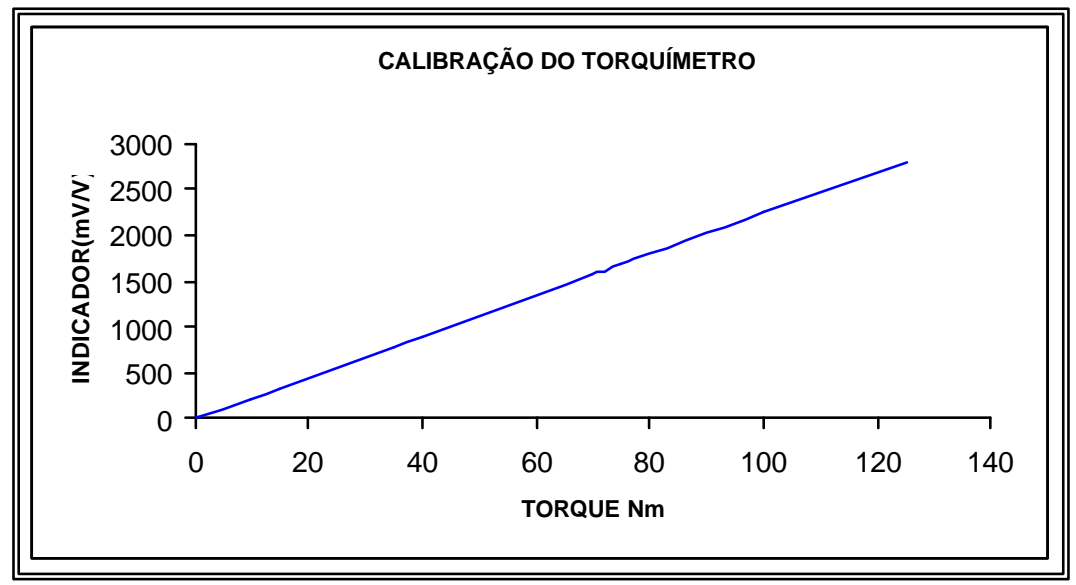

FIGURA 16 - Gráfico demonstrativo torque/indicador da calibração do torquímetro.

Com a substituição da célula de carga $\operatorname{Kratos}^{\circledR}$ pelo torquímetro, foram dispensados os componentes que controlavam seu posicionamento (haste de fixação, suporte quadrado, superfície em acrílico). O desenho esquemático da versão final do PTO é apresentado na FIGURA 17. 


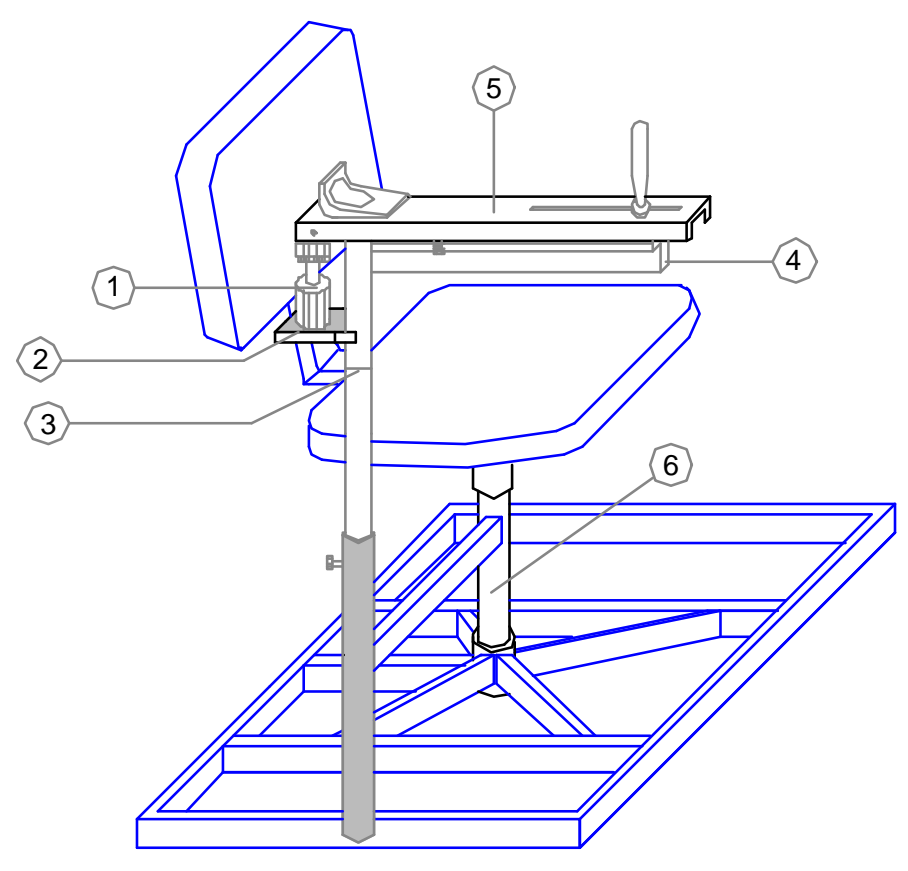

FIGURA 17 - Desenho esquemático da versão final do PTO: 1) torquímetro; 2) suporte para fixação do torquímetro; 3) cremalheiras; 4) barra de apoio do braço de alavanca, 5) haste de apoio do antebraço e 6 ) eixo de fixação da cadeira.

\subsubsection{Base de sustentação do PTO}

O sistema de acoplamento da plataforma de medição do torque à base de sustentação do PTO também foi alterado.

Um dos tubos telescopáveis foi excluído e o tubo remanescente foi interposto por duas cremalheiras circulares com 36 (trinta e seis) dentes, permitindo seu travamento a cada 10 graus, totalizando 360 graus de liberdade para amplitude de rotação dos ombros. Este sistema permite a avaliação bilateral dos ombros, através do giro da plataforma de medição do torque.

O ajuste das cremalheiras foi realizado através de um parafuso utilizado para liberação e travamento das cremalheiras na angulação desejada. Uma mola afasta as 
cremalheiras em sentido axial quando da liberação do parafuso. A FIGURA 18 demonstra o sistema de controle da angulação de rotação do tubo telescopável.

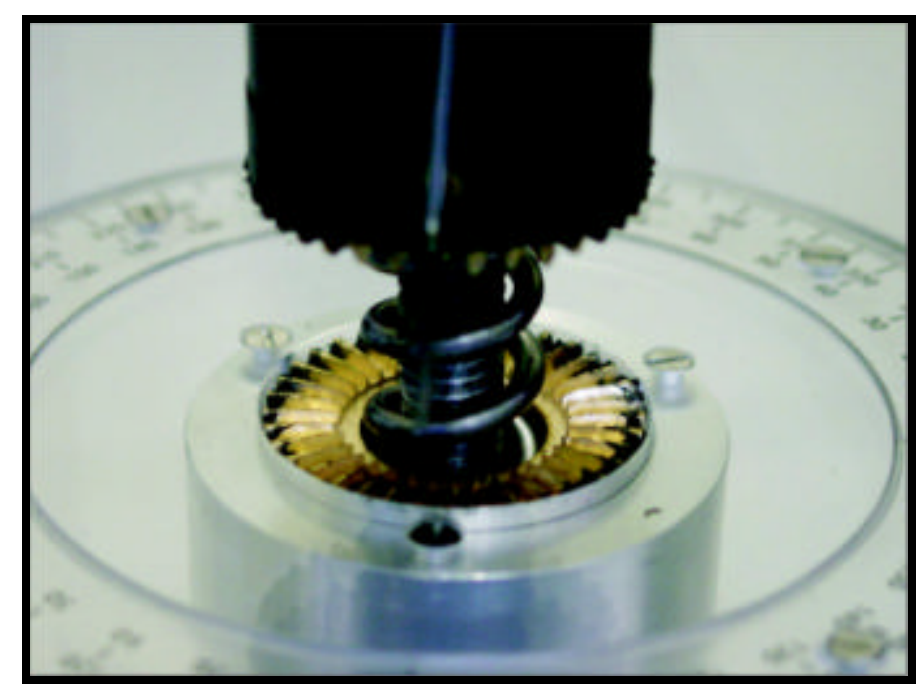

FIGURA 18 - Sistema de controle da angulação de rotação do tubo telescopável.

Para receber o torquímetro foi soldado um suporte com três furos na porção proximal do tubo telescopável de sustentação. Ainda neste local, uma barra de aço em formato "T", denominada de barra de apoio do braço de alavanca, foi soldada em sentido oposto ao suporte para o torquímetro a fim de fornecer uma base à haste de apoio do antebraço.

Na porção média desta barra de aço um orifício permite seu travamento à haste de apoio do antebraço por um parafuso, sem gerar aperto ou contato entre as peças, entretanto, limitando movimentos da haste de apoio do antebraço no plano sagital.

Dois orifícios com rosca, na porção distal da barra de apoio do braço de alavanca, receberam parafusos com ponta esférica em "teflon" que servem para 
minimizar o eventual atrito entre a haste de apoio do antebraço e a barra de aço em "T".

Para a avaliação bilateral dos ombros, foi feito um sistema diferenciado no eixo da cadeira que possibilita o giro e travamento do assento a 180 graus.

Os detalhamentos destes componentes podem ser vistos nos apêndices C e D.

\subsubsection{Haste de apoio do antebraço}

Uma nova haste de apoio para o antebraço foi confeccionada em perfil de alumínio e formato em "U". Uma abertura na porção distal superior possibilitou o acoplamento do manípulo, desta vez, através de um sistema de porca quadrada na porção inferior que permite seu deslizamento. Esta alteração facilitou o posicionamento do manípulo, além de possibilitar completa adaptação às variações no comprimento do antebraço dos indivíduos.

Um corte de $1 \mathrm{~mm}$ de espessura ao longo da porção inferior da haste limita o contato direto desta com a barra de apoio do braço de alavanca.

Sobre a haste de apoio do antebraço foi fixada uma escala em acrílico para medida do comprimento do braço de alavanca, eliminando o uso de fita métrica.

Um goniômetro, também em acrílico, foi acoplado abaixo das cremalheiras e um ponteiro facilita a visualização da angulação testada. As FIGURAS 19 e 20 mostram a haste de apoio do antebraço com a escala e o goniômetro. 


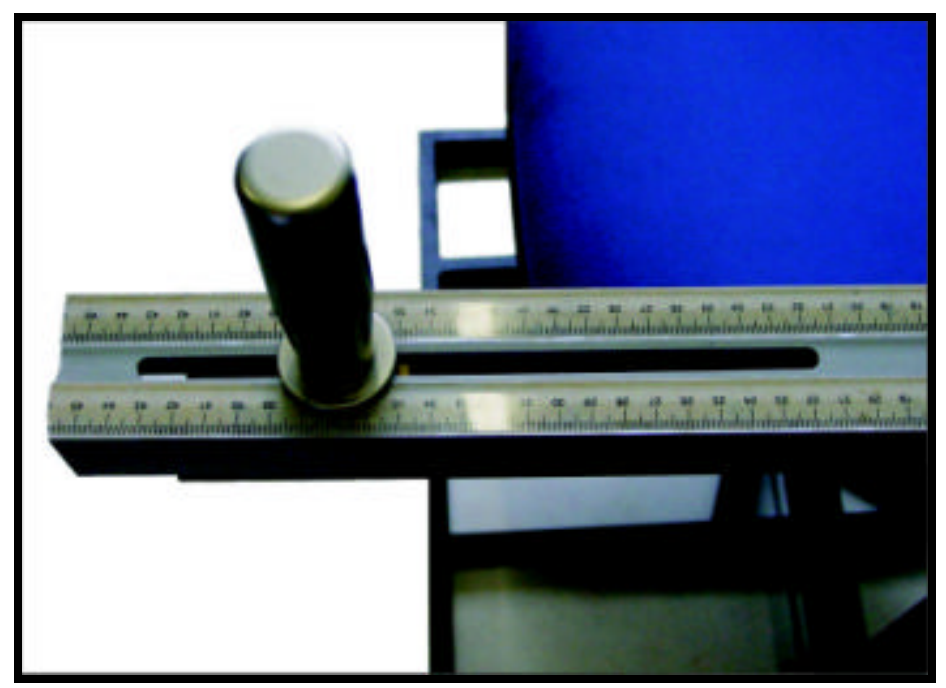

FIGURA 19 - Haste de apoio do antebraço com escala em centímetros.

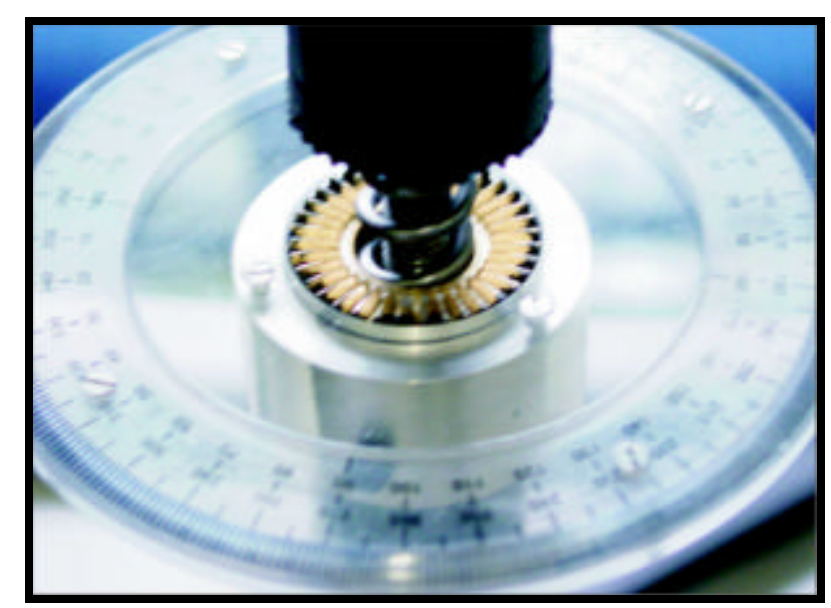

FIGURA 20 - Goniômetro fixado sob as cremalheiras.

\subsection{TESTE DE EFICIÊNCIA E ADAPTABILIDADE DA VERSÃO FINAL DO PTO}

A versão final do aparelho também foi submetida aos testes de eficiência e adaptabilidade, com o mesmo procedimento de teste utilizado para o protótipo. Os parâmetros de análise foram observados durante os testes de esforços isométricos de rotação dos ombros de dez voluntários saudáveis. 
Os resultados foram observados considerando o protótipo e a versão final da Plataforma Torsional do Ombro. Os parâmetros analisados incluíram: 1) a adaptação do aparelho às variações antropométricas dos indivíduos; 2) a eficácia do PTO na avaliação do torque dos rotadores do ombro e 3) o nível de tolerância relatada pelos indivíduos durante os testes. As FIGURAS 21 e 22 apresentam a versão final do aparelho desenvolvido para avaliar o torque de rotação interna e rotação externa do ombro.

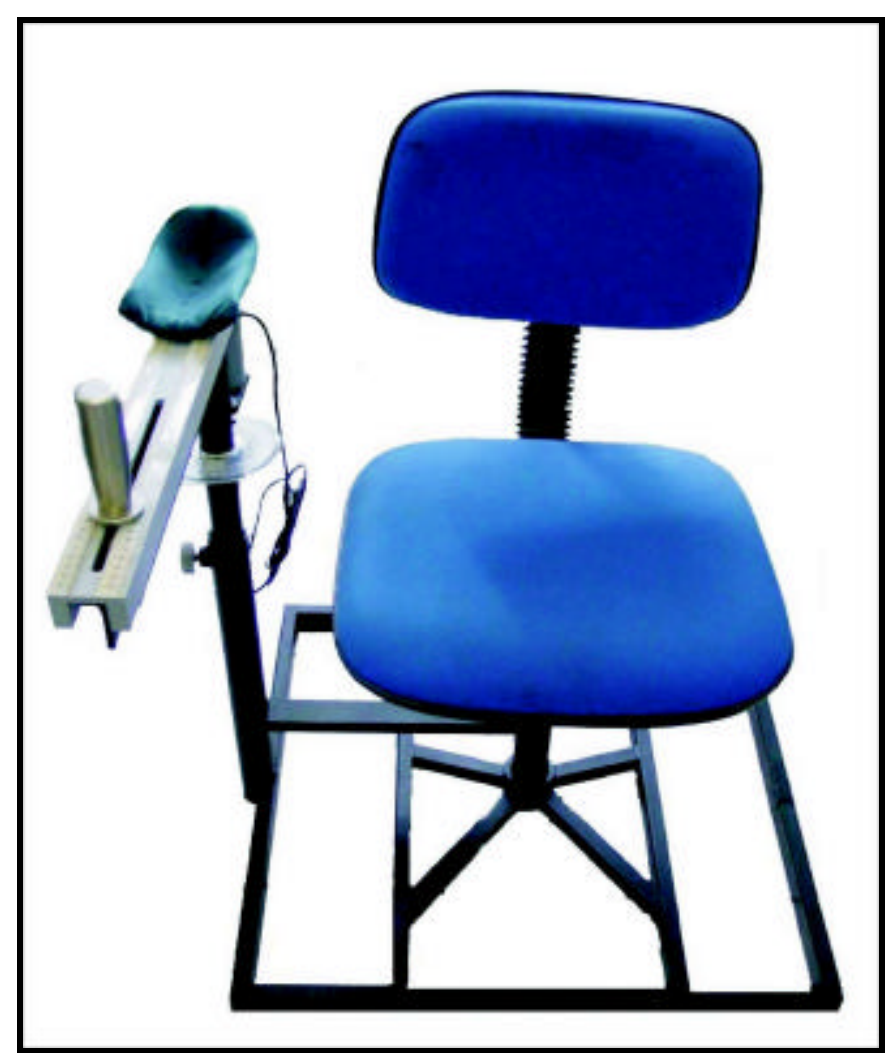

Figura 21 - Versão final do PTO 


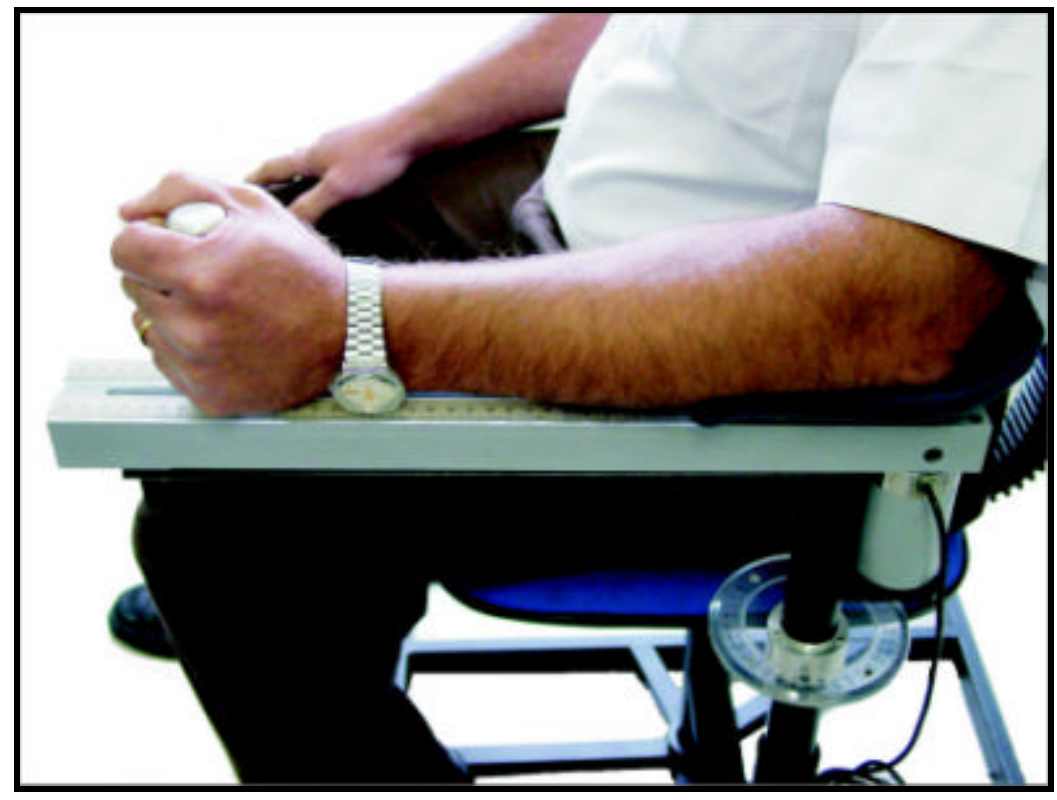

Figura 22 - Vista lateral da versão final do PTO

\subsection{ADAPTAÇÃO DO PTO ÀS VARIAÇÕES ANTROPOMÉTRICAS DOS INDIVÍDUOS}

O aparelho desenvolvido apresentou eficiência na adaptação às variações antropométricas dos indivíduos, tanto para o membro superior e inferior, como para o apoio do tronco e posicionamento do ombro no plano da escápula. Na versão final do PTO estas adaptações foram mais facilmente controladas.

A somatória da liberdade de ajustes permitida pelo aparelho possibilitou sua utilização inclusive em crianças. Em um trabalho paralelo, publicado no $\mathrm{X}$ Congresso Brasileiro de Biomecânica, o protótipo do PTO foi utilizado na avaliação do ombro em crianças e adolescentes, demonstrando adaptação favorável às variações na estatura (ROSA et al., 2003). 


\subsection{EFICÁCIA DO PTO NA AVALIAÇÃO DA FORÇA MUSCULAR DOS ROTADORES DO OMBRO}

Tanto o protótipo quanto a versão final do PTO foram eficazes na avaliação do torque isométrico dos rotadores do ombro. Todas as angulações de rotação do ombro puderam ser avaliadas, incluindo aquelas observadas em indivíduos com frouxidão cápsulo-ligamentar, onde a amplitude de movimento é maior que a média considerada padrão.

Os torques obtidos durante os testes isométricos de rotação do ombro utilizando o PTO foram semelhantes àqueles observados na literatura, em trabalhos que envolviam a utilização de equipamentos sofisticados e de alto custo, como os dinamômetros isocinéticos.

Eventuais influências de contrações musculares do antebraço e mão durante a realização dos testes utilizando o protótipo foram, a princípio, eliminadas com a adaptação do torquímetro na versão final. Este instrumento de medida, colocado no eixo de rotação do ombro, não responde a esforços mecânicos de tração ou compressão dos segmentos, enfatizando a veracidade nos resultados obtidos com os testes do torque dos rotadores.

\subsection{TOLERÂNCIA RELATADA PELOS INDIVÍDUOS SUBMETIDOS AOS ESFORÇOS ISOMÉTRICOS UTILIZANDO O PTO}

Os voluntários submetidos aos testes de eficiência e adaptabilidade do PTO relataram não sentir dor ou desconforto durante a realização dos testes. $\mathrm{O}$ posicionamento adotado para os testes foi facilmente atingido, o que nos permite afirmar que o aparelho desenvolvido poderá ser utilizado tanto em ombros saudáveis 
quanto em ombros patológicos, sendo útil inclusive como método auxiliar no diagnóstico das disfunções do ombro, em especial, naquelas relacionadas às doenças do manguito rotador.

\subsection{CUSTO APROXIMADO DO APARELHO DESENVOLVIDO PARA} AVALIAR O TORQUE DOS ROTADORES DO OMBRO

O custo do PTO foi estimado levando em consideração os gastos com materiais para a confecção da versão final, a ponte de extensometria, a mão-de-obra de usinagem e montagem, a mão-de-obra elétrica e o acabamento. O custo aproximado para a confecção do PTO foi de US\$ 400,00 (quatrocentos dólares). 
Os pontos principais desse trabalho residem na necessidade de quantificar e padronizar o sistema de avaliação da força muscular, com a finalidade de identificar disfunções e determinar o potencial da reabilitação funcional nos portadores de doenças musculoesqueléticas do ombro.

No exercício da reabilitação, podemos observar que o empirismo e a subjetividade limitam a qualidade dos serviços prestados, desde a avaliação do paciente até a apresentação dos resultados obtidos com o tratamento.

A integridade da força muscular é fundamental na fase de recuperação dos processos patológicos do sistema musculoesquelético e principalmente na prevenção deles.

Os testes manuais de força muscular são subjetivos, sendo definidos como métodos de medição semiquantitativos. SCHWARTZ, COHEN \& HERBISON (1992) alegaram que estes testes são convenientes e de fácil realização durante a reabilitação, entretanto, estes autores compararam o desempenho dos testes manuais e instrumentais para medir a força muscular nos membros superiores e concluíram que a medida instrumental é mais rigorosa e fidedigna que a manual, sendo capaz de demonstrar o ganho progressivo da força com o decorrer do processo de reabilitação.

BEASLEY (1961) demonstrou que existe uma correlação muito baixa entre as medidas manuais da força muscular e as medidas obtidas com dinamômetros. Em seus estudos, este autor verificou que músculos que apresentavam redução de $50 \%$ da capacidade normal de gerar força foram considerados normais com a utilização dos testes manuais.

Por outro lado, equipamentos sofisticados como os dinamômetros isocinéticos, considerados como instrumentos de alta precisão e confiabilidade na 
avaliação da força muscular apresentam alto custo. Estes equipamentos só são adquiridos, de um modo geral, em grandes centros de pesquisa e reabilitação.

Além disso, a relação custo/benefício da utilização destes equipamentos para o membro superior é contraditória.

Para HUGHES et al., (1999) resultados mais precisos foram obtidos através da avaliação isométrica comparada a isocinética para articulação do ombro. Segundo os autores, parece existir uma tolerância menor dos indivíduos para testes isocinéticos do ombro se comparado aos mesmos testes em outras articulações. Os autores relataram ainda que pacientes com comprometimento do manguito rotador apresentam dificuldades significativas durante a realização do teste isocinético.

Segundo RABIN \& POST (1990) somente 31\% dos indivíduos teriam sucesso com o teste de força isocinética do ombro. Esses autores relataram que melhores resultados foram obtidos com avaliação isométrica.

ELSNER et al., (1983) utilizaram o CYBEX II e descreveram que o posicionamento para teste é pobremente tolerado por sujeitos com comprometimento do manguito rotador, história de dor e subluxações do ombro.

CAHALAN et al., (1989), IVEY et al., (1985) e KUHLMAN et al., (1992) alegaram que os resultados obtidos durante os testes com equipamentos isocinéticos são menos influenciados por erro no posicionamento dos indivíduos.

No corpo humano, a dependência do equilíbrio das forças musculares é mais evidente nas articulações do ombro. Transtornos no desempenho da força muscular geram limitações funcionais e progressivamente estruturais deste segmento.

As articulações do ombro têm pouca estabilidade óssea e dependem muito da integridade da força muscular, diferentemente das outras articulações do corpo. 
Os músculos do manguito rotador são os principais responsáveis pela estabilização e equilíbrio dinâmico do ombro e geralmente estão incluídos nos processos patológicos da cintura escapular. O conhecimento da capacidade funcional desses músculos é essencial para efeitos de diagnóstico e tratamento deste segmento.

O exame palpatório sempre foi um método auxiliar na identificação da atividade muscular. A palpação dos rotadores externos não oferece dificuldades, porém o mesmo não pode ser dito sobre os rotadores internos. O principal rotador interno (subescapular) localiza-se entre a escápula e o gradil costal, e seu exame palpatório não é uma tarefa simples.

O desenvolvimento do aparelho para avaliar a força isométrica dos rotadores do ombro surgiu da necessidade vivenciada nos serviços de ortopedia e fisioterapia que trabalham com o membro superior. Nesses setores, vários instrumentos de medida para os rotadores do ombro foram improvisados a fim de identificar possíveis distúrbios nestes músculos. A maioria destes instrumentos improvisados incluía a utilização de tubos ou faixas elásticas ligadas a uma balança de uso doméstico, outras vezes, por meio de compressões sobre esfigmomanômetros.

Desde o início, o objetivo desse trabalho foi desenvolver um aparelho para avaliar a força muscular dos rotadores do ombro. Muitas questões foram levantadas a esse respeito. Uma delas se refere ao fato de avaliarmos apenas rotadores em uma articulação com tantos músculos e com a maior mobilidade encontrada no corpo humano. Em resposta a esta questão, lembramos que os demais movimentos do ombro só são permitidos em sua totalidade, quando os movimentos de rotação estão íntegros. 
Podemos verificar, por exemplo, que os movimentos de abdução e de flexão do ombro só podem ser completados com associação do movimento de rotação externa. Do mesmo modo, a extensão depende do movimento de rotação interna do ombro.

Além disso, a maioria das patologias ortopédicas do ombro está associada ao déficit funcional do manguito rotador. Dentre elas, podemos citar a bursite subacromial, a tendinite do supra-espinhoso e a síndrome do impacto.

Uma outra questão se relacionava ao fato de existirem equipamentos importados de alta tecnologia e mundialmente aceitos para avaliar a força muscular. Entretanto, sabemos que estes equipamentos têm um custo muito alto e, particularmente para o ombro, não apresentam aceitação satisfatória em pacientes com disfunção, sendo mais útil na avaliação de ombros normais.

Assim, desenvolvemos um aparelho para avaliar a força muscular dos rotadores do ombro, devidamente padronizado segundo as necessidades cinesiológicas do grupo muscular em questão e de acordo com os dados antropométricos descritos por WINTER (1990).

Inicialmente decidimos o padrão de posicionamento no qual os testes de força muscular seriam realizados. A posição ótima para o teste de força de rotação interna e rotação externa do ombro provavelmente é o principal alvo de controvérsias.

DAVID \& MAGAREY (2000) referiram-se à atuação do bíceps braquial na rotação externa como inevitável a partir de $60^{\circ}$ de abdução.

Estudando os efeitos da posição do ombro durante a rotação, BLASCHAK (1987) estabeleceu que a rotação interna pode ser maior a $0^{\circ}$ de abdução e rotação 
externa é maior a $90^{\circ}$ de abdução.

Para WALNSLEY \& SZIYBBO (1987) a rotação externa foi maior a 90 de flexão do úmero.

A posição neutra parece ser a posição preferida para testar ambas as funções em termos de vantagem mecânica, permitindo aos sujeitos com ombros saudáveis ou não, alcançar a posição de teste com facilidade.

Acreditamos que o padrão de posicionamento adotado em nosso estudo minimiza a probabilidade de utilização dos grupos musculares acessórios, priorizando os rotadores primários, sendo viável tanto para ombros saudáveis como para ombros patológicos.

A preferência por avaliar a força muscular dos rotadores do ombro no plano da escápula associa-se aos fatos descritos por GREENFIELD et al., (1990) que encontraram em seus estudos, decréscimo significativo na capacidade de desempenho da força muscular isométrica para os rotadores externos, quando testados no plano frontal.

Em relação ao tipo de contração avaliada, optamos pela contração isométrica por apresentar melhor nível de tolerância durante os testes em ombros patológicos.

GOULD (1993) se refere à necessidade de incorporar todos os tipos de contração muscular (isométrica para estabilizadores, excêntrica para desaceladores e concêntrica para aceleradores) tanto na avaliação quanto para um programa terapêutico. Os músculos do manguito rotador são estabilizadores potenciais, logo, a avaliação isométrica dos mesmos parece ser mais indicada.

Os instrumentos de medida indireta (célula de carga) e direta (torquímetro) 
utilizados neste trabalho foram eficazes na avaliação da força dos rotadores, entretanto, a utilização do torquímetro na versão final do PTO facilitou os cálculos matemáticos e o manuseio do equipamento.

Os elementos do aparelho desenvolvido possuem correspondência direta com os parâmetros físicos relacionados às funções musculoesqueléticas do ombro, tornando-o de fácil entendimento e aplicação.

Algumas dificuldades encontradas com a utilização do protótipo, entretanto, podem ser relatadas. Podemos citar, por exemplo, a dificuldade em manusear a plataforma de medição da força de um lado para o outro, a cada avaliação bilateral. Um outro problema identificado na utilização do protótipo associou-se a variação no posicionamento da célula de carga e seu alinhamento com o manípulo para cada indivíduo avaliado, não constituindo um problema potencial, mas de caráter pouco prático quando vários indivíduos foram testados em série.

As dificuldades citadas foram sanadas com as alterações apresentadas na versão final do PTO e o tempo gasto com o posicionamento do ombro na angulação de rotação desejada foi atenuado com a implementação do goniômetro e das cremalheiras circulares.

O nível de cooperação e motivação dos ndivíduos durante a realização dos testes influencia o resultado do torque obtido, tendo sido a principal dificuldade encontrada na realização deste trabalho. A distração tem que ser reduzida ao mínimo e o indivíduo deve apresentar o máximo de dedicação durante o teste, para que as margens de erro nos valores obtidos sejam minimizadas.

Estipulamos cuidadosamente o posicionamento do indivíduo durante a avaliação, o tempo de contração muscular e os intervalos entre os esforços a fim de 
obtermos resultados mais precisos, porém, o método de avaliação da força muscular utilizado neste trabalho também tem suas limitações.

Não sabemos o grau de atividade da musculatura acessória e também não podemos afirmar que os motores primários da rotação do ombro apresentavam atividade total e de forma constante durante os esforços isométricos realizados. Um estudo eletromiográfico concomitante poderia amenizar este problema.

Ainda assim, podemos afirmar que o PTO atende às necessidades de exame diagnóstico da força muscular de rotação do ombro, com precisão na apresentação dos resultados. Seu uso não causa compressão das estruturas subacromiais, possibilitando sua aplicação em várias etapas terapêuticas a fim de acompanhar quantitativamente a evolução dos quadros de disfunção muscular do ombro.

O baixo custo do aparelho desenvolvido para avaliar o torque dos rotadores do ombro possibilita sua aquisição pelos diversos centros de ortopedia e reabilitação do membro superior. 
Os resultados do presente trabalho permitiram as seguintes conclusões:

1. O aparelho desenvolvido demonstrou eficácia na avaliação isométrica da força muscular dos rotadores do ombro.

2. Este aparelho permite a avaliação dos músculos rotadores do ombro em toda amplitude deste movimento, bilateralmente, sendo adaptável às variações antropométricas.

3. A utilização do aparelho desenvolvido não causa desconforto, possibilitando seu uso em ombros com disfunção, constituindo um método auxiliar no diagnóstico das lesões do manguito rotador e no acompanhamento dos processos de recuperação das desordens musculoesqueléticas do ombro. 
6. REFERÊNCIAS BIBLIOGRÁFICAS 
ADRIAN, M. \& COOPER, J.: Biomechanics of Human Movement. Boston McGrawHill, 1995.

AMADIO, A.: Fundamentos Biomecânicos para a Análise do Movimento Humano. Universidade de São Paulo, 1996.

ANDRADE, R. P.; PIRES, P. R.; PEREIRA, J. A. R.: Compressão do nervo supraescapular: Avaliação de 07 casos. Revista Brasileira de Ortopedia, 28, 645-49, 1993.

ANDRADE, R. P.; SILVA, E. S.; VIEIRA, J.S.: Avaliação da força dos rotadores externos e internos do ombro em atletas de voleibol. Revista. Brasileira de Ortopedia, 31, 727-730, 1996.

BACKMAN, E.; JOHNSSON, V.; HAGER, B.: Isometric muscle strength and muscular endurance in normal persons aged between 17 and 70 years. Scand Journal. Rehabilitation Medicine. 27: 109-117, 1995.

BASTI, J. J.: Rehabilitation of the frozen shoulder. Article Orthopedic Hospital New York, 1992.

BEASLEY,W. C.: Quantitative muscle testing: Principles and aplication to research and clinical services. Archives of Physical Medicine and Rehabilitation, 42, 398425, 1961.

BLANC, Y. \& VIEL, E.: Comportement moteur du membre supérieur. Encycl. Méd. Chir., Kinésithérapie, Reeducation fonctionnelle, 26-012-D-10, 16, 1994.

BLASCHAK, M. J.: Shoulder internal and external rotation peak torque production through a velocity spectrum in differing positions. Journal Orthopedic. and Sports Physical Therapy, 8: 518-524, 1987. 
BROWN, L. P.; NEIHVES, S. L.; HARRAH, A.: Upper extremity range of motion and Isokinetic strength of the internal and external shoulder rotators in major league baseball players. American Journal Sports Medicine. 16: 577, 1988.

BROWNER, B. D.; JÚPITER, J. B.; LEVINE, A. M.; TRAFTON, P. G.: Traumatismos do Sistema musculoesquelético. Ed. Manole, 2000.

BURNHAM, R. S; MAY, L.; NELSON, REID, D. C.: Shoulder pain in wheelchair athletes: The role of muscle imbalance. American Journal of Sports Medicine, 21 (2), 238-242, 1993.

CAHALAN, T. D; JONSON, M. E; CHAO, E. Y. S.: Shoulder strength analysis using the Cybex II Isokinetic Dynamometer. Clinical Orthopaedics and Related Research, 249-257, 1989.

CANAVAN, P. K.: Reabilitação em Medicina Esportiva. Ed. Manole, 2001.

CHANG, D. E.; BUSCHBACHER, L. P.; EDLICH, R. F.: Limited joint mobility in power lifter. American Journal Sports Medicine 16: 280, 1988.

CIULLO, J. V.: Shoulder injuries in sports. Evaluation, treatment and rehabilitation. Human kinetics, Champaign, 1996.

CRAIG, E. V.: "Ombro e braço”. In: WEINSTEIN S. L. \& BUCKWALTER J. A, Ortopedia de Turek: Princípios e sua aplicação. Ed. Manole, 2000.

DANIELS, L. \& WORTHINGHAN, C.: Muscle testing: tecniques of manual examination. 5 ed. Philadelphia, W. B. Saunders, 1986.

DAVIES,G. J.: Isokinetic charactheristics of professional football players narrative relationships between quadríceps an hamstrings muscle goups and relations to body weight. Rev. Med. Sci. Sports Exerc. 13 (2):76, 1981. 
DAVID, G. \& MAGAREY, M. E.: EMG and strength correlate of selected shoulder muscles during rotations of the glenohumeral joint. Clinical Sports Medicine 15 (2): 95-102, 2000.

DUVALL, E. N.: Critical analysis of divergent views of movement at the shoulder joint. Archives Physical Medicine Rehabilitation, 36: 149-53, 1955.

ELLENBECKER T. S. \& DERSCHEID, G. L.: Reabilitation of overuse injuries in the shoulder. Clinical Sports Medicine. 8: 583, 1988.

ELSNER, R. C.; PEDEGANA, L. R.; LANG, J.: Protocol for strength testing and rehabilitation of the upper extremity. Journal Orthopedic. and Sports Physical Therapy. 4: 229-235, 1983.

FERRARI, D. A.: Capsular ligaments of the shoulder. American Journal Sports Medicine 18: 20, 1990.

FENOLL, R. M. S: Servei de Dinamometria. Disponível em: < http://www.iiqab.csic.es/servdinamocat.htm >. Acesso em: 06 de março de 2002.

FONGEMIE, A. E; BUSS, D. D.; ROLNICK, S. J.: Management of shoulder Impingement syndrome and rotador cuff tears- The American Academy of family Physicians. February-15, 1998.

FREEDMAN, L. \& MUNRO, R. R.: Abduction of the arm in the scapular plane: scapular glenohumeral movements. Journal Bone Joint Surgery. 48: (1) 503-10, 1966.

GODINHO, G. G.; SANTOS, F. M. L; FREITAS, J. M. A.: Avaliação da força muscular e da função do ombro após reparo do manguito rotador. Revista Brasileira de Ortopedia. 29: 643-646, 1994. 
GOULD, J. A.: Fisioterapia na ortopedia e na medicina do esporte. Ed. Manole, 1993.

GREENFIELD, B. H.; DONATELLI, R. A.; WOODEN, M. J.: Isokinetic evaluation of shoulder rotational strength between plan of scapula and functional plane. American Journal Sports Medicine, 18: 124, 1990.

HARRYMAN, D. T; SIDLES, J. A.; CLARK, J. M.; MATSEN, F. A.: Translation of the humeral head on the glenoid with passive glenohumeral motion. The Journal of Bone and Joint Surgery. 72 A, N. 9. October. 1334-1343, 1990.

HERTOGH, C.; CHAVET, P.; GAVIRIA, M.; MELIN, B.; JIMENEZ, C.:Méthodes de Mesure et Valeurs de Référence de la Puissance Maximale Développée lors Dfforts Explosifs. Cinesiologie, 133-140, 1994.

HISLOP, H. P.\& MONTGOMERY,J.: Daniels \& Worthingham - Provas de função muscular. 6 ed. Ed. Guanabara Koogan, 1996.

HUGHES, R. E; JOHNSON, M. E; O'DRISCOLL, S.W.: Age-related changes in normal isometric shoulder strength. American Journal of Sports Medicine, 27, $\mathrm{n}^{\circ} 5$, 651-657, 1999.

INMAN, V. T.; SAUNDERS, J. R.; ABBOUTT, J. C.: Observations on the function of the shoulder joint. Journal Bone Joint Surgery, 26: 1-30, 1944.

IVEY, F. M.; CALHOUN, J.R.; RUSCHE, K.: Isokinetic testing of shoulder strength: normal values. Archives Physical Medicine and Rehabilitation. 66: 384386, 1985.

JAOVISIDHA, S. \& JACOBSON, J.A.: M.R. imaging of rotator cuff tears: is there a diagnostic benefit of shoulder prior to imaging. Jul-Aug. University California, 1999. 
JOBE, F. W. \& PINK, M.: Classification and treatment of shoulder dysfunction in the overhead athlete. Journal of Orthopedics and Sports Physical Therapy, 18 (2): 427-432, 1993.

JOBE, C. M.: Gross anatomy of the shoulder. In: Rockwood, C.A.; MATSEN, F. A.; The shoulder. Philadelphia. W. B. Saunders; 1-33, 1990.

KALTENBORN, F. M. 1980.: Mobilization of the extremity joints. In SOUZA,2001.

KAPANDJI, I. A.: Fisiologia articular. Ed.Manole, 1990.

KIBLER, W. B.: Biomechanical analysis of the shoulder during tennis activities. Clinical Sports Medicine, 14: 79-85, 1995.

KIOSCHOS, J. M.: Shoulder anatomy. Disponível em: <http:// www.theshoulderdoc.com>. Acesso em: 23 de junho de 2002.

KUHLMAN, J. R; IANNOTTI, J. P; MARTIN, J. K.: Isokinetic and isometric measurement of strength of external rotation and abduction of the shoulder. The Journal of Bone and Joint Surgery. 74 A - n 9, October, 1992.

LECH, O.: Fundamentos em cirurgia do ombro. Ed. Harbra Ltda, 1995.

MALONE, T. R.; McPOIL, T.; NITZ, A. J.: Fisioterapia em Ortopedia e Medicina no Esporte. Ed.Santos, 2000.

MATSEN, F. A. \& ARNTZ, C. T.: Subacromial impingement, In: ROCKWOOD, C. A. \& MATSEN, F. A.; The shoulder. W. B. Saunders, Philadelphia, 1990. 
McCANN, P. D; WOOTTEN, M. E; BIGLIANI, L.: A kinematical and electromyographic study of shoulder rehabilitation exercises. Clinical Orthopaedics and Related Research, 1992.

MORRISON, D. S.; FRONGAMENI, A. D.; WOODWORTH, P.: Non-operative treatment of subacromial impingement syndrome. Journal Bone Joint Surgery., 79 (5): 7327, 1997.

MURRAY, M. P; GORE, D. R; GARDNER, G. M.: Shoulder motion and muscle strength of normal men and woman in two age groups. Clinical Orthopaedic., 192: 268-273, 1985.

NEER, C. S.: Anterior acromioplasty for the chronic impingement syndrome in the shoulder: a preliminary study. Journal Bone Joint Surgery., 54: 41-50, 1972.

NEER, C. S.: Impingement lesions. Clinical Orthopaedic., 173: 70-7, 1983.

NEER, C. S.: Fractures about the shoulder. In ROCKWOOD, C. A. Fractures in Adults. W. B. Saunders, 1984.

NETTER, F. H.: Atlas of Human Anatomy. Icon Learning Systems, 1996.

NORBERG, F. B. \& FIELD, L. D.: Repair of the rotator cuff, mini-open and arthroscopic repair. Mississippi Sport Medicine. Jan, 2000.

NORKIN, C. \& WHITE, D.: Measurement of joint Motion: A guide to goniometry, Ed. F. D. DAVIS, Philadelphia .

OTIS, J. C; WARREN, R. F; BACKUS, S. I.: Torque production in the shoulder of the normal young adult male. American Journal Sports Medicine, 18: 119-123, 1990. 
OVESEN, J. \& NIELSEN, S.: Stability of the shoulder joint: cadaver study of stabilizing structures. Acta Orthophedics Scandinavia 56: 149, 1985.

PAYNE, L. Z.; DENG, X.; CRAIG, E. V.; WARREN, R. F.: The combined dynamic and static contributions to subacromial impingement. A biomechanical analysis. The American Journal of Sports Medicine; 25, nº 801-807, 1997.

PEARN, J.: Two dynamometers: An historical account of the earliest measurements to study human muscular strength. Journal of Neurological Sciences, 37, 127-34, jun., 1978.

PEAT, M.: Functional anatomy of the shoulder complex. Physical Therapy, 66 (12): 1855-65, 1986.

POPPEN, N. K. \& WALKER P.S.: Normal and abnormal motion of the shoulder. Journal Bone Joint Surgery. 58: 195-201, 1976.

RABIN, S. I \& POST, M.: A comparative study of clinical muscle testing and CYBEX evaluation after shoulder operation. Clinical Orthophaedics. 25; 147-156, 1990.

REID, D. C; SABOE, L.; BURHAM, R.: Current research in selected shoulder problems. In DONATELLI, R. Physical therapy of the Shoulder, 1987.

ROSA, R. S.; SILVA, P.; SOUSA, F. A.; SOUZA, P. M.; MAZZER, N.; BARBIERI, C. H.; SHIMANO, A. C.: Desempenho de força muscular isométrica do ombro em crianças e adolescentes de ambos os sexos. Anais do X Congresso Brasileiro de Biomecânica, p.230. Ouro Preto - MG. 2003.

ROCKWOOD, C. A. \& MATSEN, F. A.:The shoulder. W. B. Saunders, 1990. 
SARRAFIAN, S. K.: Gross and functional anatomy of the shoulder. Clinical Orthophaedics, 173: 11-18, 1983.

SAVOIE, F. H.: Thermal versus suture treatment of symptomatic capsular laxity. Mississippi Sports Medicine. Jan, 2000.

SCHWARTZ, S.; COHEN, M. E.; HERBISON, G. J.: Relationship between two measures of upper extremity strength: Manual muscle test compared to hand held myometry. Archives of Physical Medicine and Rehabilitation, 37, 1036-68, nov. 1992.

SHINZATO, G. \& BATISTELLA, L. R.: Exercício isocinético: sua utilização para avaliação e reabilitação musculoesquelético. Âmbito Medicina Desportiva, $\mathrm{n}^{\circ} 1,11$ $18,1996$.

SMITH, L. K.; WEISS, E. L.; LEHMKUHL, L. D.: Cinesiologia clínica de Brunnstron. Ed. Manole, 1997.

SOUZA, M. Z.: Reabilitação do complexo do ombro. Ed. Manole, 2001.

SPEER, K. P.: Anatomy and pathomechanics of shoulder instability. Clinics Sports Medicine. 14 (4) 751-760, 1995.

WALMSLEY, R. P; \& SZYBBO, C.: A comparative study of the torque generated by the shoulder internal and external rotador muscles in different positions and at varying speeds. Journal Orthopedic and Sports Physical Therapy. 217-222, 1987.

WARWICH, R. \& WILLIANS, P.: Grays anatomy. W.B. Saunders, 1973.

WEINECK, J.: Manual de Treinamento Esportivo. Ed. Manole, 1989.

WEINECK, J.: Biologia do esporte.Ed. Manole, 2000. 
WHITING, W. C\& ZERNICKE, R. F.: Biomecânica da lesão musculoesquelética. Ed. Guanabara Koogan, 2001.

WINTER, D. A.: Biomechanics and motor control of human movement. Ed. Interscience Publications, 1990. 


\section{Anexo A - Termo de Consentimento}

\section{TERMO DE CONSENTIMENTO}

Nome da pesquisa: "Uso de aparelho mecânico na quantificação de força dos rotadores do ombro".

Responsável pelo projeto: Patrícia Moura Souza

Instituição: Pós-Graduação Interunidades em Bioengenharia FMRP, EESC, IQSC/USP.

$\mathrm{Eu}$,

RG $\mathrm{n}^{\mathrm{o}}$........................................, abaixo assinado,concordo em participar deste estudo, tendo recebido informações sobre os objetivos, justificativas e procedimentos que serão adotados durante a sua realização assim como os benefícios que poderão ser obtidos.

Autorizo a publicação das informações por mim fornecidas com a segurança de que não serei identificado e de que será mantido o caráter confidencial da informação relacionada com a minha privacidade.

Tendo ciência do exposto acima, assino esse termo de consentimento. 


\section{Anexo B - FORMULÁRIO DE AVALIAÇÃO DO OMBRO}

A)Dados pessoais:

Nome:

Idade:

Sexo:

Profissão:

Atividade esportiva:

Dominância: D ( ) E ( ) Bilateral ( )

Altura:

Peso:

B) Dados antropométricos:

1- Comprimento do braço (tubérculo maior ao epicôndilo lateral) D: $\mathrm{cm}$.

$\mathrm{E}: \_\mathrm{cm}$

2- Comprimento do antebraço (olecrano ao processo estilóide da ulna) D: $\mathrm{cm}$.

E:__cm

C) Auto-avaliação:

1- Você está com dor no ombro?

Assinale a resposta correta: $\operatorname{Sim}($ ) Não ( )

2- Sente seu ombro instável (como se fosse luxar)?

Quanto é instável o seu ombro? (marcar na linha).

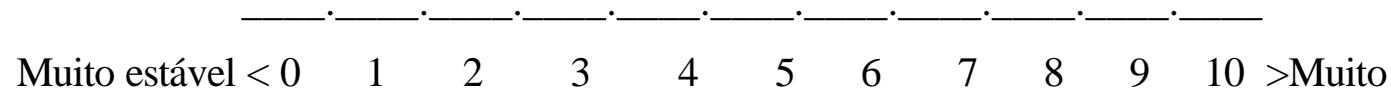

instável

D) Assinalar o número na caixa que indica a sua capacidade de realizar as atividades seguintes:

0- Incapaz de efetuar;

1- Muito difícil de efetuar;

2- Um pouco difícil;

3- Não difícil; 


\begin{tabular}{|l|c|c|}
\hline \multicolumn{1}{|c|}{ Atividade } & Braço direito & Braço esquerdo \\
\hline 1- Vestir uma camisa & 0123 & 0123 \\
\hline 2- Dormir sobre o lado afetado ou doloroso & 0123 & 0123 \\
\hline 3- Lavar as costas/ abotoar o sutiã nas costas & 0123 & 0123 \\
\hline 4- Pentear o cabelo & 0123 & 0123 \\
\hline 5- Alcançar uma prateleira & 0123 & 0123 \\
\hline 6- Atirar uma bola com a mão & 0123 & 0123 \\
\hline 7- Efetuar trabalho usual \{ & 0123 & 0123 \\
\hline 8- Fazer esporte usual \{ & 0123 & 0123 \\
\hline
\end{tabular}

E) Amplitude de movimento - Achados do examinador :

\begin{tabular}{|l|l|l|}
\hline \multicolumn{1}{|l|}{} & Direito & Esquerdo \\
\hline Movimento total do ombro & ativo passivo & ativo passivo \\
\hline Elevação anterior ( ângulo máximo braço/tronco) & & \\
\hline Rotação externa (braço ao lado) & & \\
\hline Rotação externa ( braço em abdução a 90 & \\
\hline Rotação interna (mais alta anatomia posterior alcançada c/ polegar) & & \\
\hline Rotação interna ( braço em abdução a 90 & & \\
\hline Adução transversal do corpo(fossa antecubital ao acrômio oposto) & & \\
\hline
\end{tabular}

\section{F) Sinais:}

\begin{tabular}{|c|c|c|c|}
\hline Sinal & \multicolumn{2}{|c|}{ Direito } & Esquerdo \\
\hline Dor à palpação do supra-espinhoso/ tuberosidade maior & Sim & Não & Sim Não \\
\hline Dor à palpação da acrômio-clavicular & Sim & Não & Sim Não \\
\hline Dor a palpação do tendão bíceps (ou ruptura) & Sim & Não & Sim Não \\
\hline Outra dor à palpação _ & Sim & Não & Sim Não \\
\hline Colisão 1 ( elevação passiva à frente em rotação interna leve) & Sim & Não & Sim Não \\
\hline Colisão 2 ( rotação interna passiva à $90^{\circ}$ de flexão) & Sim & Não & Sim Não \\
\hline Colisão 3 ( Abdução a 90 arco doloroso clássico) & Sim & Não & Sim Não \\
\hline Crepitação subacromial & Sim & Não & Sim Não \\
\hline Cicatrizes - localização_ & Sim & Não & Sim Não \\
\hline Atrofia - localização_ & Sim & Não & Sim Não \\
\hline Deformidade - descrever_ & Sim & Não & Sim Não \\
\hline
\end{tabular}


G) Força (avaliação manual):

$0=$ Ausência de contração;

$1=$ Lampejo (esboço);

2= Movimento com gravidade eliminada;

3= Movimento contra a gravidade;

4= Movimento contra alguma resistência;

$5=$ Força normal;

\begin{tabular}{|l|c|c|}
\hline & Direito & Esquerdo \\
\hline Teste de força afetado por dor & Sim Não & Sim Não \\
\hline Elevação anterior & 012345 & 012345 \\
\hline Abdução & 012345 & 012345 \\
\hline Rotação externa (braço ao lado do corpo) & 012345 & 012345 \\
\hline Rotação Interna (braço ao lado do corpo) & 012345 & 012345 \\
\hline
\end{tabular}

H) Avaliação quantitativa da força dos rotadores do ombro

Posição do corpo: individuo com tronco devidamente apoiado no encosto, sem rotação ou inclinação, sem compensação de apoio do membro superior contra lateral, membros inferiores não submetidos a aplicação de força e apoiados na base da cadeira.

Posição do membro avaliado: braço ao lado do corpo, cotovelo fletido a $90^{\circ}$, antebraço sobre apoio e em posição neutra, ombro no plano da escápula e abdução de 15 graus.

\begin{tabular}{|c|c|c|}
\hline & Braço direito & Braço esquerdo \\
\hline Força de rotação externa 1 (ombro em posição neutra) & & \\
\hline Força de rotação externa 2 (ombro a $30^{\circ}$ de rotação externa) & & \\
\hline Força de rotação externa 3 (ombro a $30^{\circ}$ de rotação interna) & & \\
\hline Força de rotação interna 1 (ombro em posição neutra) & & \\
\hline Força de rotação externa 2 (ombro a $30^{\circ}$ de rotação externa) & & \\
\hline Força de rotação interna 3 (ombro a $30^{\circ}$ de rotação interna) & & \\
\hline
\end{tabular}


I) Instabilidade

$0=$ Nenhuma

1= Branda (translação 0-1 cm).

2= Moderada (translação 1-2 cm)

$3=$ Grave $(>2 \mathrm{~cm}$ de translação ou sobre o rebordo glenóideo)

\begin{tabular}{|c|c|c|}
\hline Translação anterior & 0123 & 0123 \\
\hline Translação posterior & 0123 & 0123 \\
\hline Translação inferior (sinal do sulco) & 0123 & 0123 \\
\hline Apreensão anterior & 0123 & 0123 \\
\hline Reproduz sintomas? & Sim & Sim \\
\hline Instabilidade voluntária & Sim & Sim \\
\hline Frouxidão ligamentar generalizada & Sim & Sim \\
\hline
\end{tabular}

Outros achados físicos:

Nome do examinador

Fonte: BROWNER et al., 2000. 


\section{Apêndice A - Tabelas dos torques obtidos com a utilização do protótipo.}

\section{Tabela 1 -}

Valores dos torques de rotação externa $(\mathrm{Nm})$ na posição neutra, a $30^{\circ} \mathrm{RE}$ e a $30^{\circ} \mathrm{RI}$.

\begin{tabular}{l|l|l|l|l}
\hline \multicolumn{5}{c}{ Dominante } \\
\hline Idade-Sexo & Dominância & RE neutra & RE a 30 RE & RE a 30 RI \\
\hline $27-\mathrm{M}$ & Direita & 23,87 & 19,6 & 25,86 \\
\hline $35-\mathrm{M}$ & Direita & 21,97 & 20,67 & 29,34 \\
\hline $36-\mathrm{M}$ & Direita & 23,94 & 17,06 & 27,65 \\
\hline $36-\mathrm{M}$ & Direita & 19,87 & 14,77 & 28,79 \\
\hline $40-\mathrm{M}$ & Direita & 29,37 & 28,7 & 32,67 \\
\hline $38-\mathrm{M}$ & Direita & 33,47 & 24,01 & 37,18 \\
\hline $25-\mathrm{F}$ & Direita & 11,12 & 8,62 & 11,74 \\
\hline $27-\mathrm{F}$ & Direita & 11,42 & 11,72 & 11,84 \\
\hline $40-\mathrm{F}$ & Direita & 9,74 & 7,74 & 15,99 \\
\hline $26-\mathrm{F}$ & Direita & 6,11 & 4,82 & 7,17 \\
\hline
\end{tabular}

Tabela 2-

Valores dos torques de rotação externa $(\mathrm{Nm})$ na posição neutra, a $30^{\circ} \mathrm{RE}$ e a $30^{\circ} \mathrm{RI}$.

\begin{tabular}{l|l|l|l|l}
\hline Não Dominante & RE neutra & RE a 30 RE & RE a 30 RI \\
\hline Idade-Sexo & Dominância & 15,64 & 12,56 & 20,94 \\
\hline $27-\mathrm{M}$ & Direita & 18,81 & 18,22 & 27,93 \\
\hline $35-\mathrm{M}$ & Direita & 20,10 & 15,87 & 22,22 \\
\hline $36-\mathrm{M}$ & Direita & 23,56 & 15,79 & 18,85 \\
\hline $36-\mathrm{M}$ & Direita & 34,39 & 27,91 & 35,58 \\
\hline $30-\mathrm{M}$ & Direita & 30,73 & 20,3 & 38,27 \\
\hline $37-\mathrm{M}$ & Direita & 10,09 & 6,61 & 8,82 \\
\hline $25-\mathrm{F}$ & Direita & 7,13 & 6,62 & 11,33 \\
\hline $40-\mathrm{F}$ & Direita & 7,10 & 6,12 & 10,04 \\
\hline $26-\mathrm{F}$ & Direita & 5,76 & 5,29 & 7,47 \\
\hline
\end{tabular}


Tabela 3-

Valores dos torques de rotação interna $(\mathrm{Nm})$ na posição neutra, a $30^{\circ} \mathrm{RI}$ e a $30^{\circ} \mathrm{RE}$.

Dominante

\begin{tabular}{l|l|l|l|l}
\hline Idade-Sexo & Dominância & RI neutra & RI a 30 RI & RI a 30 RE \\
\hline $27-\mathrm{M}$ & Direita & 30,97 & 28,13 & 38,08 \\
\hline $35-\mathrm{M}$ & Direita & 36,13 & 35,41 & 44,52 \\
\hline $36-\mathrm{M}$ & Direita & 34,66 & 30,29 & 37,04 \\
\hline $36-\mathrm{M}$ & Direita & 37,2 & 28,66 & 40,51 \\
\hline $40-\mathrm{M}$ & Direita & 46,83 & 44,58 & 48,15 \\
\hline $37-\mathrm{M}$ & Direita & 51,17 & 44,17 & 51,86 \\
\hline $25-\mathrm{F}$ & Direita & 19,86 & 17,99 & 15,61 \\
\hline $27-\mathrm{F}$ & Direita & 15,54 & 12,86 & 15,92 \\
\hline $40-\mathrm{F}$ & Direita & 14,49 & 12,99 & 15,24 \\
\hline $26-\mathrm{F}$ & Direita & 11,17 & 7,99 & 14,46 \\
\hline
\end{tabular}

Tabela 4-

Valores dos torques de rotação interna (Nm) na posição neutra, a $30^{\circ} \mathrm{RI}$ e a $30^{\circ} \mathrm{RE}$.

\begin{tabular}{l|l|l|l|l}
\hline Não Dominante & \multicolumn{5}{l}{} \\
\hline Idade-Sexo & Dominância & RI neutra & RI a 30 RI & RI a 30 RE \\
\hline $27-\mathrm{M}$ & Direita & 30,44 & 28,48 & 34,63 \\
\hline $35-\mathrm{M}$ & Direita & 31,16 & 27,28 & 43,51 \\
\hline $36-\mathrm{M}$ & Direita & 33,86 & 28,84 & 35,05 \\
\hline $36-\mathrm{M}$ & Direita & 32,99 & 17,58 & 36,94 \\
\hline $40-\mathrm{M}$ & Direita & 43,92 & 41,01 & 47,49 \\
\hline $37-\mathrm{M}$ & Direita & 49,52 & 47,47 & 51,17 \\
\hline $25-\mathrm{F}$ & Direita & 15,55 & 12,86 & 16,95 \\
\hline $27-\mathrm{F}$ & Direita & 13,63 & 13,12 & 13,75 \\
\hline $40-\mathrm{F}$ & Direita & 13,23 & 11,76 & 14,45 \\
\hline $26-\mathrm{F}$ & Direita & 9,99 & 7,52 & 12,41 \\
\hline
\end{tabular}




\section{Apêndice B - Tabelas dos torques obtidos com a utilização da versão final do PTO.}

Tabela 1 -

Valores dos torques de rotação externa $(\mathrm{Nm})$ na posição neutra, a $30^{\circ} \mathrm{RE}$ e a $30^{\circ} \mathrm{RI}$.

\begin{tabular}{l|l|l|l|l}
\hline & \multicolumn{3}{|c}{ Dominante } \\
\hline Idade-Sexo & Dominância & RE neutra & RE a 30 RE & RE a 30 RI \\
\hline $31-\mathrm{M}$ & Direita & 29,62 & 23,64 & 29,97 \\
\hline $34-\mathrm{M}$ & Direita & 28,74 & 22,49 & 33,96 \\
\hline $32-\mathrm{M}$ & Direita & 22,85 & 20,68 & 24,29 \\
\hline $36-\mathrm{M}$ & Direita & 27,23 & 25.37 & 29,73 \\
\hline $28-\mathrm{M}$ & Direita & 33,89 & 26,43 & 36,18 \\
\hline $30-\mathrm{M}$ & Direita & 35,91 & 32,64 & 36,21 \\
\hline $26-\mathrm{F}$ & Direita & 17,43 & 14,26 & 18,32 \\
\hline $36-\mathrm{F}$ & Direita & 13,14 & 12,21 & 12,43 \\
\hline $38-\mathrm{F}$ & Direita & 15,97 & 11,47 & 17,98 \\
\hline & Direita & 18,27 & 16,79 & 18,91
\end{tabular}

Tabela 2-

Valores dos torques de rotação externa (Nm) na posição neutra, a $30^{\circ} \mathrm{RE}$ e a $30^{\circ} \mathrm{RI}$.

\section{Não Dominante}

\begin{tabular}{l|l|l|l|l}
\hline Idade-Sexo & Dominância & RE neutra & RE a 30 RE & RE a 30 RI \\
\hline $31-\mathrm{M}$ & Direita & 29,98 & 31,98 & 28,91 \\
\hline $34-\mathrm{M}$ & Direita & 25,26 & 33,47 & 28,96 \\
\hline $32-\mathrm{M}$ & Direita & 21,94 & 30,72 & 23,43 \\
\hline $36-\mathrm{M}$ & Direita & 29,54 & 30,49 & 28,19 \\
\hline $28-\mathrm{M}$ & Direita & 31,86 & 27,31 & 33,17 \\
\hline $30-\mathrm{M}$ & Direita & 36,41 & 31,93 & 33,23 \\
\hline $26-\mathrm{F}$ & Direita & 16,98 & 13,26 & 17,46 \\
\hline $36-\mathrm{F}$ & Direita & 14,11 & 12,36 & 11,99 \\
\hline $38-\mathrm{F}$ & Direita & 15,13 & 10,98 & 16,41 \\
\hline
\end{tabular}


Tabela 3-

Valores dos torques de rotação interna $(\mathrm{Nm})$ na posição neutra, a $30^{\circ} \mathrm{RI}$ e a $30^{\circ} \mathrm{RE}$.

Dominante

\begin{tabular}{l|l|l|l|l}
\hline Idade-Sexo & Dominância & RI neutra & RI a 30 RI & RI a 30 RE \\
\hline $31-\mathrm{M}$ & Direita & 36,94 & 42,28 & 49,24 \\
\hline $34-\mathrm{M}$ & Direita & 44,63 & 31,23 & 40,34 \\
\hline $32-\mathrm{M}$ & Direita & 37,89 & 31,99 & 39,78 \\
\hline $36-\mathrm{M}$ & Direita & 42,97 & 36,41 & 34,27 \\
\hline $\mathbf{2 8 - \mathrm { M }}$ & Direita & 36,95 & 29,87 & 39,36 \\
\hline $30-\mathrm{M}$ & Direita & 41,42 & 40,76 & 46,29 \\
\hline $\mathbf{2 6 - \mathrm { F }}$ & Direita & 23,14 & 21,98 & 24,17 \\
\hline $\mathbf{2 6 - \mathrm { F }}$ & Direita & 21,96 & 20,33 & 23,16 \\
\hline $31-\mathrm{F}$ & Direita & 22,14 & 19,18 & 26,11 \\
\hline $38-\mathrm{F}$ & Direita & 29,36 & 23,66 & 31,18 \\
\hline
\end{tabular}

Tabela 4-

Valores dos torques de rotação interna $(\mathrm{Nm})$ na posição neutra, a $30^{\circ} \mathrm{RI}$ e a $30^{\circ} \mathrm{RE}$.

\begin{tabular}{l|l|l|l|l}
\hline Não Dominante & RI neutra & RI a 30 RI & RI a 30 RE \\
\hline Idade-Sexo & Dominância & 44,27 & 43,23 & 48,97 \\
\hline $31-\mathrm{M}$ & Direita & 46,38 & 42,97 & 39,98 \\
\hline $34-\mathrm{M}$ & Direita & 37,27 & 30,18 & 38,88 \\
\hline $32-\mathrm{M}$ & Direita & 44,93 & 34,23 & 43,21 \\
\hline $\mathbf{3 6 - \mathrm { M }}$ & Direita & 34,27 & 27,99 & 38,17 \\
\hline $30-\mathrm{M}$ & Direita & 40,48 & 38,27 & 42,16 \\
\hline $26-\mathrm{F}$ & Direita & 22,11 & 18,36 & 24,12 \\
\hline $\mathbf{2 6 - \mathrm { F }}$ & Direita & 20,99 & 18,98 & 21,98 \\
\hline $31-\mathrm{F}$ & Direita & 23,16 & 21,17 & 27,39 \\
\hline $38-\mathrm{F}$ & Direita & 29,98 & 26,42 & 31,14 \\
\hline
\end{tabular}


Apêndice C - Desenho esquemático da plataforma de medição da força utilizada no protótipo.

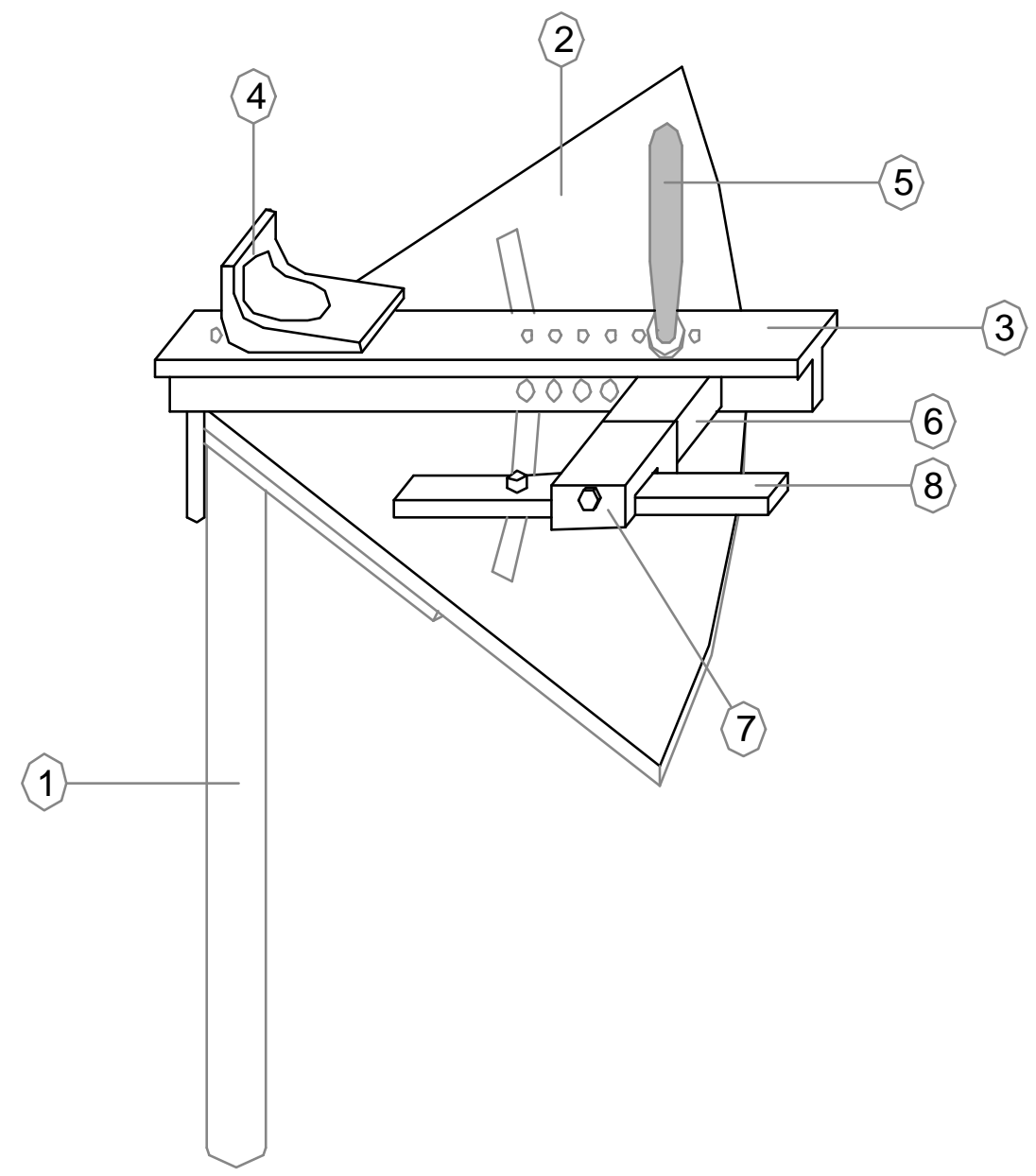

1) tubo telescopável; 2) plataforma em acrílico; 3) haste de apoio do antebraço; 4) apoio de cotovelo; 5) manípulo; 6)célula de carga; 7) suporte quadrado de fixação da célula de carga e 8) haste de fixação da célula de carga. 
Apêndice D - Desenho esquemático da plataforma de medição do torque utilizada na versão final do PTO.

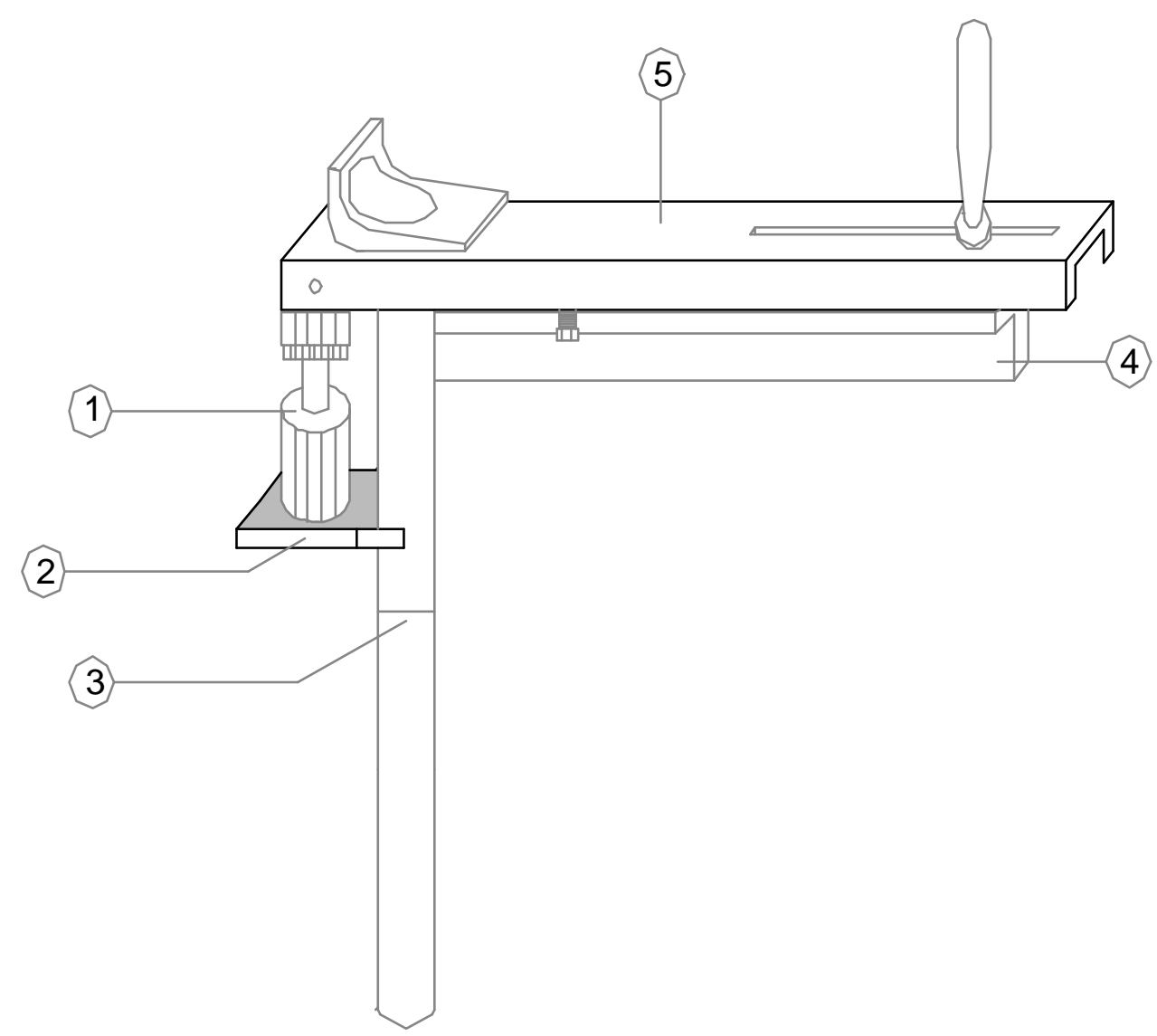

1) torquímetro; 2) suporte de apoio para o torquímetro; 3) cremalheiras interpostas; 4) barra de apoio do braço de alavanca e 5) haste de apoio do antebraço. 